\title{
The Spatial Exposure of the Chinese Infrastructure System to Flooding and Drought Hazards
}

\author{
Xi Hu${ }^{1}$, Jim Hall ${ }^{1,2}$, Peijun Shi ${ }^{3}$ and Wee Ho Lim ${ }^{1,2}$
}

${ }^{1}$ Environmental Change Institute, Oxford Centre for the Environment, School of Geography and the Environment, University of Oxford, Oxford, OX1 3QY; PH (+44)1865-275846; FAX (+44)1865-275850; email: xi.hu@ouce.ox.ac.uk, jim.hall@eci.ox.ac.uk; weeho.lim@ouce.ox.ac.uk.

${ }^{2}$ Oxford Martin School, University of Oxford, Oxford, OX1 3BD UK

${ }^{3}$ State Key Laboratory of Earth Surface Processes and Resource Ecology, Beijing Normal University, Beijing, China; PH (+86) 10-58808179; FAX (+86) 1058802158; email: spj@bnu.edu.cn.

\begin{abstract}
Recent rapid urbanisation means that China has invested in an enormous amount of infrastructure, much of which is vulnerable to natural hazards. This paper investigates from a spatial perspective how the Chinese infrastructure system is exposed to flooding and drought hazards. Infrastructure exposure across three different sectors - energy, transport and waste - is considered. With a database of 10,561 nodes and 2,863 edges that make up the three infrastructure networks, we develop a methodology assigning the number of users to individual infrastructure assets and conduct hotspot analysis by applying the Kernel density estimator. We find that infrastructure assets in Anhui, Beijing, Guangdong, Hebei, Henan, Jiangsu, Liaoning, Shandong, Shanghai, Tianjin, Zhejiang - and their 66 cities - are exceptionally exposed to flooding, which affects sub-sectors including rail, aviation, shipping, electricity and wastewater. The average number of infrastructure users who could be disrupted by the impacts of flooding on these sectors stands at 103 million. The most exposed sub-sectors are electricity and wastewater $(20 \%$ and
\end{abstract}


$14 \%$ of the total respectively). For drought hazard, we restrict our work to the electricity sub-sector, which is potentially exposed to water shortages at hydroelectric power plants and cooling water shortage at thermos-electric power plants, where the number of highly exposed users is 6 million. Spatially, we demonstrate that the southern border of Inner Mongolia, Shandong, Shanxi, Hebei, north Henan, Beijing, Tianjin, southwest of Jiangsu - and their 99 cities - are especially exposed. Whilst further work is required to understand infrastructure's sensitivity to hazard loading, the results already provide evidence to inform strategic infrastructure planning decisions.

Keywords: Exposure; flooding; drought; infrastructure (energy, electricity, waste, transport, rail, aviation, shipping); China 


\section{1. Introduction}

2

China has overtaken the United States and the EU to become the world's largest investor in infrastructure (Dobbs et al. 2013). The country has invested 8.5\% of its GDP into its infrastructure since 1992 and its stock of infrastructure as a percentage of GDP is now, at $71 \%$, above the global average (Ibid). Whilst ambitious plans are in place to increase this stock even further, concerns have been raised over the extent to which its infrastructure system can withstand natural disasters such as flooding and drought. According to the Chinese Ministry of Water Resources, the 2011 floods alone resulted in the interruption of services to 28 rail links, 21,961 roads and 49 airports, and the failure of 8,516 electricity transmission lines (Ministry of Water Resources 2011). The 2012 droughts affected a substantial proportion of the Chinese water supply - thousands of reservoirs issued warnings of "exceptional low water levels" in provinces such as Hubei, Yunnan and Heilongjiang, resulting in water shortage in urban areas (Ministry of Water Resources 2012). Meanwhile, the 2011 drought caused the water level at the world's biggest hydropower plant - the Three Gorges Dam - to fall to 152.7 metres, well below the $156 \mathrm{~m}$ mark required to run its 26 turbines effectively (Stanway 2011).

This paper seeks to understand how the Chinese infrastructure system is exposed to flooding and drought impacts. We do this by taking a first step to explore the potential of disruption to infrastructure systems and the people and industries that they serve (infrastructure 'users') caused by these events. Instead of conventional impact and risk assessments that tend to focus on the people and assets directly located in floodplains and drought-prone areas, we estimate the numbers of people dependent on infrastructure assets ('users') and pinpoint locations where critical assets are concentrated in these high-risk areas. As a result, we show the locations of critical infrastructure that are exposed to risks of flooding and drought on a broad scale - and calculate the potential number of users affected should infrastructure assets fail owing to one or a series of flooding/drought event(s) on a local scale. 
The outline of the paper is organised as follows. Section 2 presents a general

34 literature review around exposure/vulnerability analysis, infrastructure network exposure/vulnerability and an introduction to the Chinese context. Section 3 describes the methodology we adopt and the data sources. Section 4 presents our results, and Section 5 discusses the assumptions, the validity of our results and the policy implications. Section 6 concludes.

\section{Literature Review}

Literature on exposure to natural hazards is often discussed in the context of natural disaster risk reduction. The IPCC SREX (Managing the Risks of Extreme

44 Events and Disasters to Advance Climate Change Adaptation) report defines risk to natural disaster as a function of hazard, exposure and vulnerability (IPCC 2012). Hazard refers to the "possible, future occurrence of natural or human-induced physical events that may have adverse effects on vulnerable and exposed elements"; exposure refers to the "inventory of elements in an area in which hazard events may occur"; vulnerability refers to the "propensity of exposed elements such as human beings, their livelihoods, and assets to suffer adverse effects when impacted by hazard events" (Ibid).

Risk-based studies are ideal because they are probabilistic assessments of possible future hazard events and their impacts (Li et al. 2012; Wu et al. 2012). Unfortunately, much of the literature has not been able to determine the probability quantitatively owing to the huge uncertainties involved and a lack of data. As such, most relevant literature for our study is in exposure and vulnerability. Given that exposure studies are usually part of broader vulnerability analyses, we review scholarly work under the general heading of "vulnerability analysis".

60

\subsection{Vulnerability analysis}

In the context of vulnerability to flooding and drought impacts, one may 64 summarise three main approaches used. These are: qualitative, potential 
consequences and impact assessment. Qualitative approaches are the first generation of vulnerability studies. These are often derived from surveys and interviews, which are sufficient for obtaining a general idea of the possible vulnerabilities to flooding and drought and particularly useful for understanding the decision-making process (De Sherbinin et al. 2007; Regmi \& Hanaoka 2011; Zarafshani et al. 2012). However, they remain largely descriptive and hard to compare across systems.

Potential consequences approaches assess the vulnerability of a system to flooding and drought impacts by looking at how the system may be affected if hazards occur (HSBC 2011; IPCC 2012; Wilhelmi \& Wilhite 2002; Lewis 2009; Dutta et al. 2003). On the other hand, impact assessments approaches examine how a system has been affected by past flooding and drought events, in contrast to potential consequences approaches where vulnerabilities are based on how a system may cope given the possibility of future flooding/droughts, often measured by population or economic impacts (World Bank 2004).

\subsection{Infrastructure network vulnerability}

Recently, vulnerability studies of the infrastructure systems and networks have sprung up owing to concerns over increasing levels of "threats", which may or may not originate from natural disasters such as flooding and drought (Mao et al. 2009; Erath et al. 2009; Marrone et al. 2013). Here we first discuss some general methods for understanding infrastructure network vulnerability, and then examine approaches taken in the context of flooding and drought disasters.

Traditionally, scholars have sought to address network vulnerability with graph/network theories. This involved using network measures focused on the centrality of a vertex in the graph, including degree centrality, betweenness, closeness, and eigenvector centrality (Dinh \& Xuan 2012). While these metrics do provide some insights into network vulnerability, they typically fail to reveal the level of network disruption for different levels of attacks (Ibid). Therefore global 
graph measures such as the number of vertices and edges have been introduced to study network connectivity performance under different attack strategies (Holme et al. 2002). Applications of such theories can be found in the Information \& Communication Technology (ICT) and the power sectors where fictional or real networks are studied (Baiardi \& Corò 2013; Bompard et al. 2013; Mao et al. 2009; Matisziw et al. 2009).

Although graph/network theories reveal vulnerable system property or vulnerable system components of an infrastructure network, they do not typically incorporate the functional aspects of the components in the network, for example power flows in the electricity sector (Dueñas-Osorio \& Vemuru 2009; Johansson \& Hassel 2010). Indeed, some scholars are in favour of using functional models and conclude that evaluating vulnerability in power networks using purely topological metrics can be misleading (Hines et al. 2010). Similarly, LaRocca and others conclude that in general, the greater the inclusion of functional characteristics, the better the estimate of the system's actual performance for a given failure scenario (LaRocca et al. 2012). However, owing to computational limitations, it is not always possible to include these functional characteristics (Ibid).

It is more often the case however, that network and functional models are used in conjunction with each other when analysing the vulnerability in interdependent networks and cascading effects (Johansson \& Hassel 2010; Bompard et al. 2013; Shuang et al. 2014; Wang et al. 2013). Depending on the time frame, Ouyang and colleagues argue that network models are helpful to design or improve the infrastructures in the long run while focusing on functional vulnerability is useful to protect them in the short term (Ouyang et al. 2009).

Unfortunately, studies that are specifically concerned with infrastructure network vulnerability due to flooding and drought disasters are rare in the literature. Most of them reside within the "potential consequences" domains as discussed in Section 2.1 and work with urban or regional scales (Tang et al. 2013; Oswald \& Treat 2013). 


\subsubsection{Infrastructure network vulnerability in China}

130

As a result of the phenomenal growth of Chinese infrastructure over the past few decades, its networks are now among the world's largest. For instance, the country's expressway network, which is already the second largest in the world, has been growing at an average of 20 per cent per year since 2000 (KPMG 2008; KPMG 2009). China's railway system - the world's third largest network - has 6 per cent of the world's track length (and rising) and carries 25 per cent of the world's traffic (Ibid). China's inland waterway transport (IWT) network is the world's largest, and the country surpassed the U.S. as the world's largest Municipal Solid Waste (MSW) generator in 2004 (World Bank 2007; World Bank 2005).

Given the scale and speed at which Chinese infrastructure networks have grown, one may postulate that these networks might be more susceptive to different threats. Some recent studies have looked at the vulnerability of Chinese infrastructure from a network perspective. For instance, applying a network model to the power and gas pipeline systems in a non-specified Chinese city, Wang and colleagues analyse interdependent responses under three types of edge disturbance strategies and propose a method for ranking critical components (Wang et al. 2013). Taking the Chinese railway system as an example, Ouyang and others select three typical complex network-based models to analyse railway accessibility and flowbased vulnerability (Ouyang et al. 2014). Using the power network of a major city in Central China as a case study, Mao and others show that the network exhibits small-world network properties and demonstrate the vulnerability of the network under selective attacks and random failures (Mao et al. 2009). Taking the power and water systems of a major city in China as an example, Wang and colleagues develop a framework for analysing the vulnerability of interdependent infrastructure systems (Wang et al., 2012). drought impacts in China - most of which reside in the "potential consequences" domain as discussed in section 2.1 - is yet scarcer. Xie and colleagues present a 
161 framework of reliability analysis, based on fragility curves, of the dike system for 162 the Taihu Basin in China (Xie et al. 2013). HSBC overlay the locations of planned

163 power stations with water scarcity maps, showing the vulnerability of power sector 164 (HSBC 2012). Our work contributes to the current literature by building an 165 infrastructure exposure map of China across multiple sectors and locations for the 166 first time. In addition, this particular exposure study not only provides an inventory 167 of infrastructure assets, but also seeks to quantify the potential scale of disruption 168 due to infrastructure failure. We do this by developing a new metric of estimating 169 the number of exposed populations who might be vulnerable to natural hazards 170 because they are either directly or indirectly dependent on the infrastructure assets 171 concerned. Therefore, the work presented here is a first study that has demonstrated 172 the exposure of Chinese infrastructure to potential direct/indirect natural hazard 173 impacts.

\section{Methodology}

Flooding and drought events might affect the infrastructure system in significant ways. Examples of flooding impacts on the infrastructure include: water-induced asset damages and temporary inaccessibility to sites such as roads.

180 Similarly, drought could result in water levels being severely lowered in 181 hydropower reservoirs and reduce the amount of cooling water for electric power generation. In this paper, we seek to provide insights into the locations of critical infrastructure exposed to flooding and drought impacts on a broad scale, and estimate the potential number of users affected on the local scale should infrastructure assets fail owing to one or a series of flooding/drought event(s). This method builds a common metric i.e. the number of users that allows the impacts of

187 flooding/drought to be compared across sectors, even though the nature of these 188 disruptions varies.

First, we introduce the general framework for understanding the infrastructure system (Figure 1), whereby infrastructure sectors and assets are

192 specified and relevant data are collected. Second, we allocate users to each 
193 infrastructure asset at the local (asset) level for each sector since the users' 194 dependence on each infrastructure asset varies according to the type of 195 infrastructure. Upon user allocation to assets, we apply a Kernel density estimation 196 to identify 'hotspots' of exposure. Fourth, flood and drought maps are overlaid onto 197 the infrastructure "hotspot" analyses in order to obtain an idea of critical 198 infrastructure assets exposed to flooding/drought on the broad scale. The output of 199 the paper translates to infrastructure hotspot maps integrated with flooding/drought 200 hazards and the number of users as a common metric to measure exposure.

201

202

203

204

205

206

207

208

209

210

211

212

213

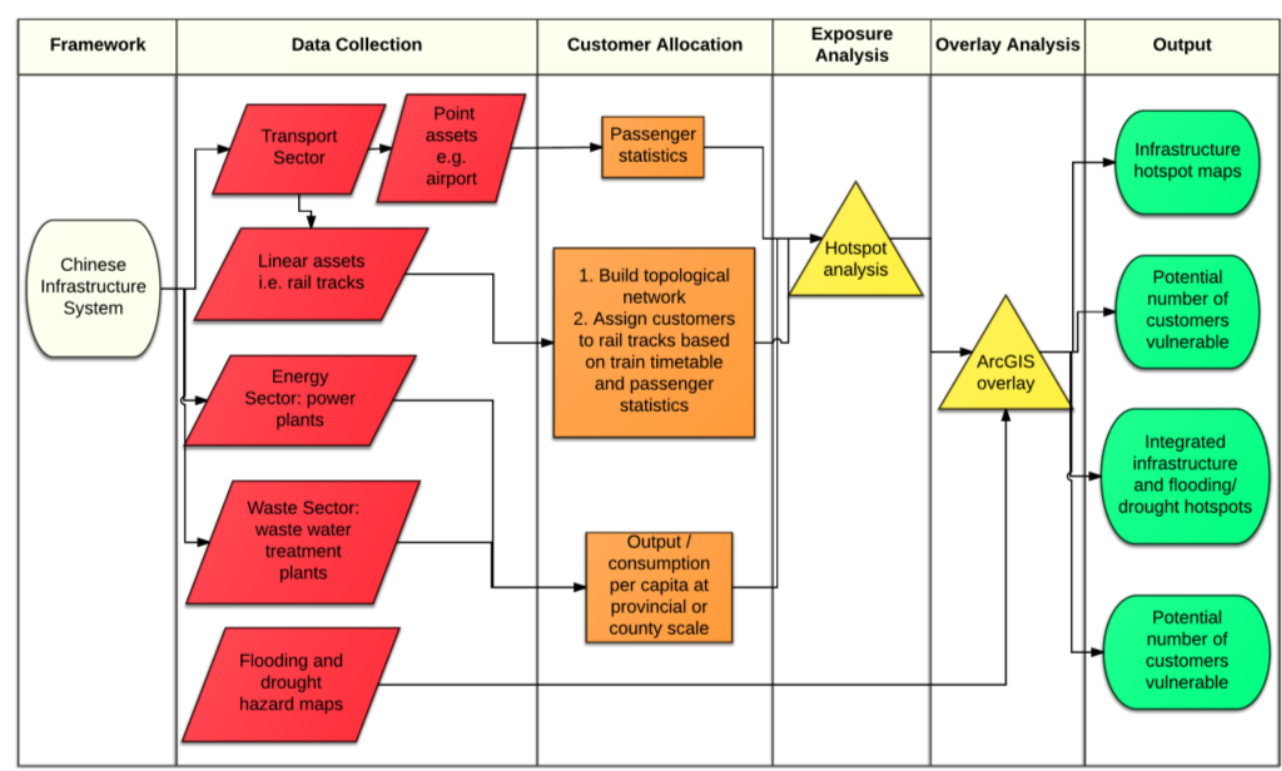

Figure 1. Overview of methodology

\subsection{Framework for understanding the Chinese infrastructure system}

We define the infrastructure system as an integrated system consisting of five sectors - energy, transport, water, waste and ICT (Hall et al. 2014). Within each of these sectors, component systems are identified and we construct an infrastructure database according to the framework shown in Table 1. 
215 Table 1. Summary of the Chinese National Infrastructure System

\begin{tabular}{|c|c|c|c|c|c|}
\hline Sector & $\begin{array}{l}\text { Sub- } \\
\text { sector }\end{array}$ & Asset type & $\begin{array}{l}\text { Number of } \\
\text { Assets }\end{array}$ & Source & $\begin{array}{l}\text { Completeness } \\
(\%)\end{array}$ \\
\hline Energy & Electricity & Power plants & 2116 & Enipedia & 67 \\
\hline \multirow[t]{4}{*}{ Transport } & \multirow[t]{2}{*}{ Rail } & Rail tracks & 2863 & OpenStreetMap & 100 \\
\hline & & Stations & 5401 & $\begin{array}{l}\text { Harvard WorldMap } \\
\text { Project }\end{array}$ & $100^{1}$ \\
\hline & Aviation & Airports & 146 & $\begin{array}{l}\text { Civil Aviation } \\
\text { Administration of China }\end{array}$ & 80 \\
\hline & Shipping & Ports & 155 & China Ports Yearbook & 3 \\
\hline Waste & $\begin{array}{l}\text { Waste } \\
\text { water }\end{array}$ & $\begin{array}{l}\text { Waste water } \\
\text { treatment works }\end{array}$ & 2743 & $\begin{array}{l}\text { Chinese Ministry of the } \\
\text { Environment }\end{array}$ & 100 \\
\hline
\end{tabular}

Source: adapted from Hu et al. (2014)

\subsubsection{Data on the electricity sub-sector}

We focus our energy work on the electricity sub-sector and obtain a total of 2,218 nodes which represent power plants from Enipedia (Davis et al. 2014). Although Enipedia contains the best open source spatial dataset that the authors are aware of, it is not complete. In Figure 2, we show the data completeness (in

224 percentage) from the Enipedia database for individual provinces by aggregating the 225 total amount of annual output produced by all power plants within each province and comparing that with official statistics on the annual electricity consumption for

227 that province from the China Electric Yearbook (China Electric Power Yearbook

228 Editorial Committee 2011). Information on provincial annual electricity

229 consumption from the China Electric Power Yearbook is digitised and translated;

230 no data are available for individual power plants nor their spatial locations hence

231 we use Enipedia and only verify the data with the China Electric Yearbook. We find

232 that data are better represented in north-eastern China; Tibet, Shaanxi and Ningxia

233 provinces have the most incomplete datasets ${ }^{2}$.

\footnotetext{
${ }^{1}$ Note no officially disclosed data exist for the total number of train stations in China. The $100 \%$ comes from personal communication with China Rail Administration (CRA). In 2010, the total number of train stations was at 5,287 . Our database with 5,401 exceeds the number provided by the CRA, thus we assume it is reasonably complete.

2 Note that Hunan province has a percentage at $101 \%$ and Jilin province at $109 \%$, which may be a reflection of data inaccuracy of the Enipedia database. In this case, Enipedia has collected power plant data, which exceed the official database's output. Data on Taiwan, Hongkong and Macao do not exist hence exhibit $0 \%$.
} 


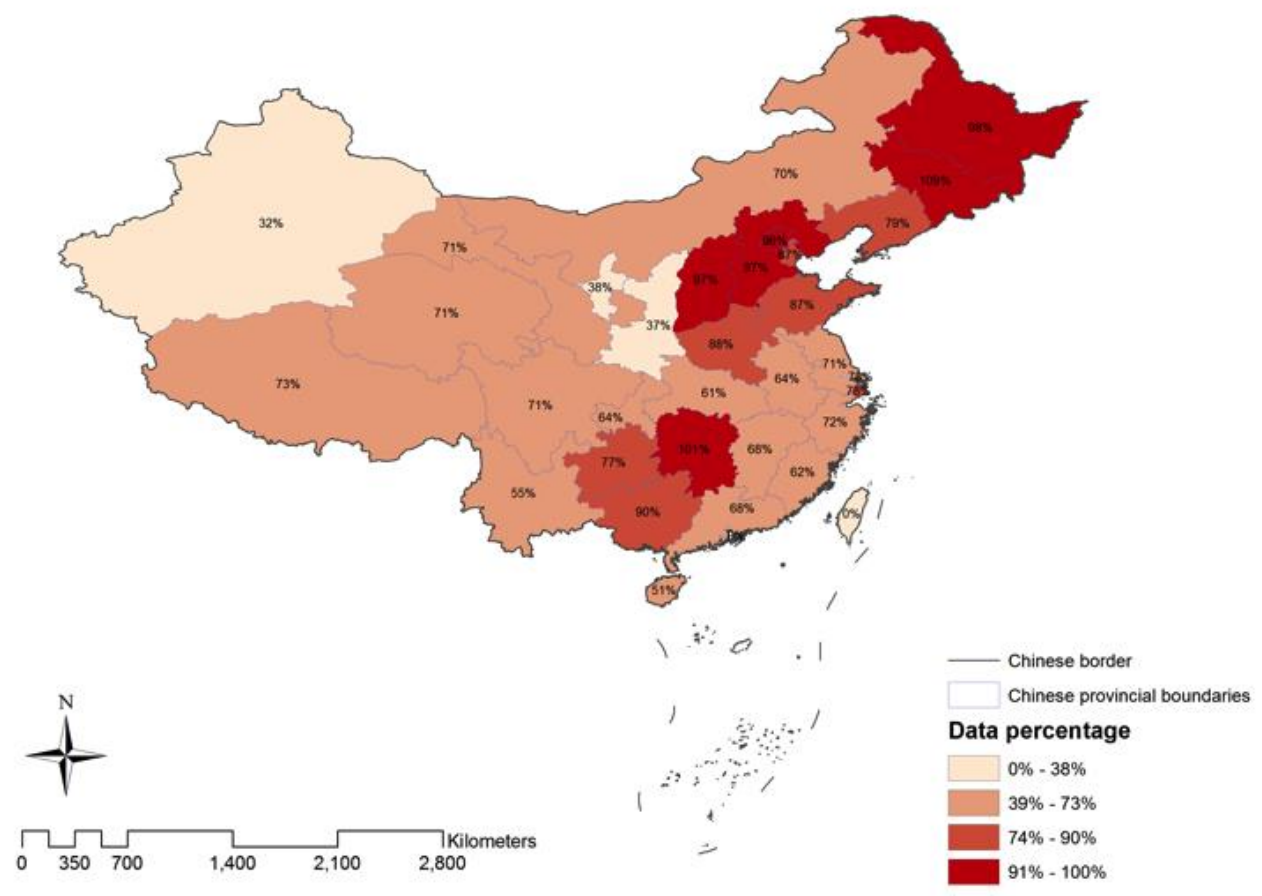

Figure 2. Data completeness (in percentage) from Enipedia's database per province in China.

\subsubsection{Data on the transport sector}

240 The total lengths for the rail network that we generate with our model (for details,

241 please refer to Section 3.2.2) in our dataset cover 138,414 km and we verify this

242 with OpenStreetMap (OpenStreetMap Contributors 2014). We assume that this

243 coverage is $100 \%$ as the Ministry of Rail reports that the total operating length of

244 the Chinese rail network extends to 98,000 km (Ministry of Rail 2012). For train

245 stations, we download data from the Harvard China Map which contains 5401 train

246 stations (The Harvard WorldMap Project 2014). For aviation, we obtain and

247 translate the list of currently operational airports (183 Chinese civil airports) and

248 those that are being planned to 2020 from the Civil Aviation Administration of

249 China (Civil Aviation Administration of China 2008; Civil Aviation Administration

250 of China 2013). This list is translated into English and 146 currently operational

251 airports are geocoded in Google Earth. In addition, we collect data on the total 
number of passengers for airports, for the year 2012, and ports, for the year 2011

253 (Civil Aviation Administration of China 2013; China Academy of Transportation

254 Sciences 2005). A VBA code is developed to match passenger data with the

255 airports in the list from the Civil Aviation Administration of China. Finally, 256 passenger data on ports come from the China Ports Yearbook and are geocoded in

257 Google Map (Editorial Board of China Ports Yearbook 2012).

\subsubsection{Data on the wastewater sub-sector}

260

A full dataset for wastewater treatment works $(2,743$ assets $)$ is obtained

262 from the Chinese Ministry of the Environment (Ministry of the Environment 2013).

263 The dataset contains full name of the treatment plant, daily capacity and city

264 information. As we do not know the exact location for each plant, we resort to a 265 thorough process of searching plant addresses online and geocoding these in 266 Google Earth and/or Baidu to our database.

\subsubsection{Data on population and administrative regions}

Population data are obtained from the "Tabulation on the 2010 population census of the people's republic of china by county" released by the Chinese Census Office (Chinese Census Office of the State Council 2012). This is one of the most recent and comprehensive datasets covering population data for China's 2,872 counties (Ibid). For each province, city, county, village and hamlets, there are detailed data on the number of residents, households and so on. We amalgamate population data with the administrative boundary data provided by Beijing Normal University in the Atlas of Natural Disasters in China (Shi 2011). 


\subsection{User allocation}

3.2.1. Transport sector - point assets

We allocate users to point assets such as airports, train stations and ports using passenger statistics based on data collected in section 3.1. As data on passenger flows for train stations do not exist, we develop a simple methodology that approximates the number of users through each station by the way it is defined (see Table 2). The Ministry of Rail (now the China Railway Corporation) classifies all railway stations into six categories, depending on the type of use (passenger, cargo, marshalling yard or a mixture), sizes of passenger flow, cargo volumes and "strategic importance" (Ministry of Rail 1980). Each station is assigned a daily passenger number using the minimum threshold given in Table 2 as a proxy. For instance, a single-use special graded station will have an average daily passenger flow of 60,000 whereas a multi-use station will have 20,000.

Table 2. Railway stations classification and their associated daily passenger and cargo volumes

\begin{tabular}{|l|l|l|l|}
\hline $\begin{array}{l}\text { Railway station } \\
\text { classification }\end{array}$ & $\begin{array}{l}\text { Railway use (passenger, } \\
\text { cargo, yard) }\end{array}$ & $\begin{array}{l}\text { Average daily } \\
\text { passenger flow }\end{array}$ & $\begin{array}{l}\text { Average daily cargo } \\
\text { volume (trucks) }\end{array}$ \\
\hline \multirow{2}{*}{ Special } & Single use & $>60000$ & $>750$ \\
\cline { 2 - 4 } & Multi-use & $>20000$ & $>450$ \\
\hline \multirow{2}{*}{2} & Single use & $>15000$ & $>350$ \\
\cline { 2 - 4 } & Multi-use & $>8000$ & $>200$ \\
\hline 3 & Single use & $>5000$ & $>200$ \\
\cline { 2 - 4 } & Multi-use & $>4000$ & $>100$ \\
\cline { 2 - 4 } & Single use & $\mathrm{n} / \mathrm{a}$ & $\mathrm{n} / \mathrm{a}$ \\
\cline { 2 - 4 } & Multi-use & $>2000$ & $>50$ \\
\hline
\end{tabular}

Source: Ministry of Rail 1980

3.2.2. Transport sector - linear assets

Assigning users to linear assets such as rail tracks is not straightforward, as 
307 allocating users to the Chinese rail sub-sector in accordance with data from train 308 timetables. First, we collect a comprehensive dataset of the 4060 Chinese "rail 309 routes", which represent all passenger rail "traffic" in China between one and three 310 days (Ministry of Rail 2010). Second, we build an approximate railway topology 311 network by assigning a straight line between every pair of stations for each "route".

312 Overlapping stations are removed. This way, one line (i.e. track) is assigned between 313 any two stations (Figure 3). Artificial straight lines are used because we have 314 incomplete data on the rail network. Third, we verify this network dataset with the 3152014 rail track dataset from OpenStreetMap ${ }^{3}$ (shown in Figure 4). Lines shorter than 316200 kilometres are well represented because they are located in densely urbanised 317 areas, therefore tend to be straight and are short in length. We replace lines that are 318 more than 200 kilometres in length with the actual track alignment because they do 319 not align well with the real tracks after verification.

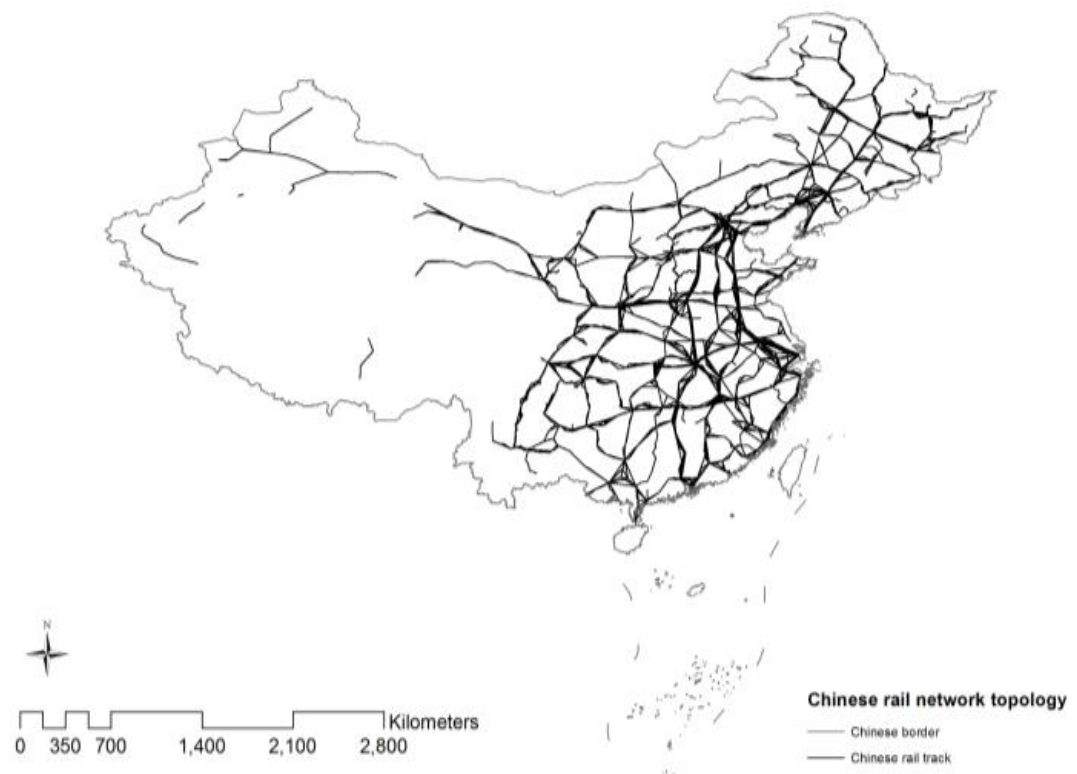

Figure 3. The Chinese railway topological network created by assigning a straight line between every pair of stations for each "route"4

\footnotetext{
3 The OpenStreetMap dataset has rail tracks and station data in separate files. This means that some stations are off the track where others have no tracks nearby. Since our "rail routes" data are stored in station-to-station format, we resort to constructing our own tracks and verify these with the OpenStreetMap tracks.

${ }^{4}$ All results in this paper do not include Taiwan, Hongkong and Macao, as data do not exist for these regions.
} 

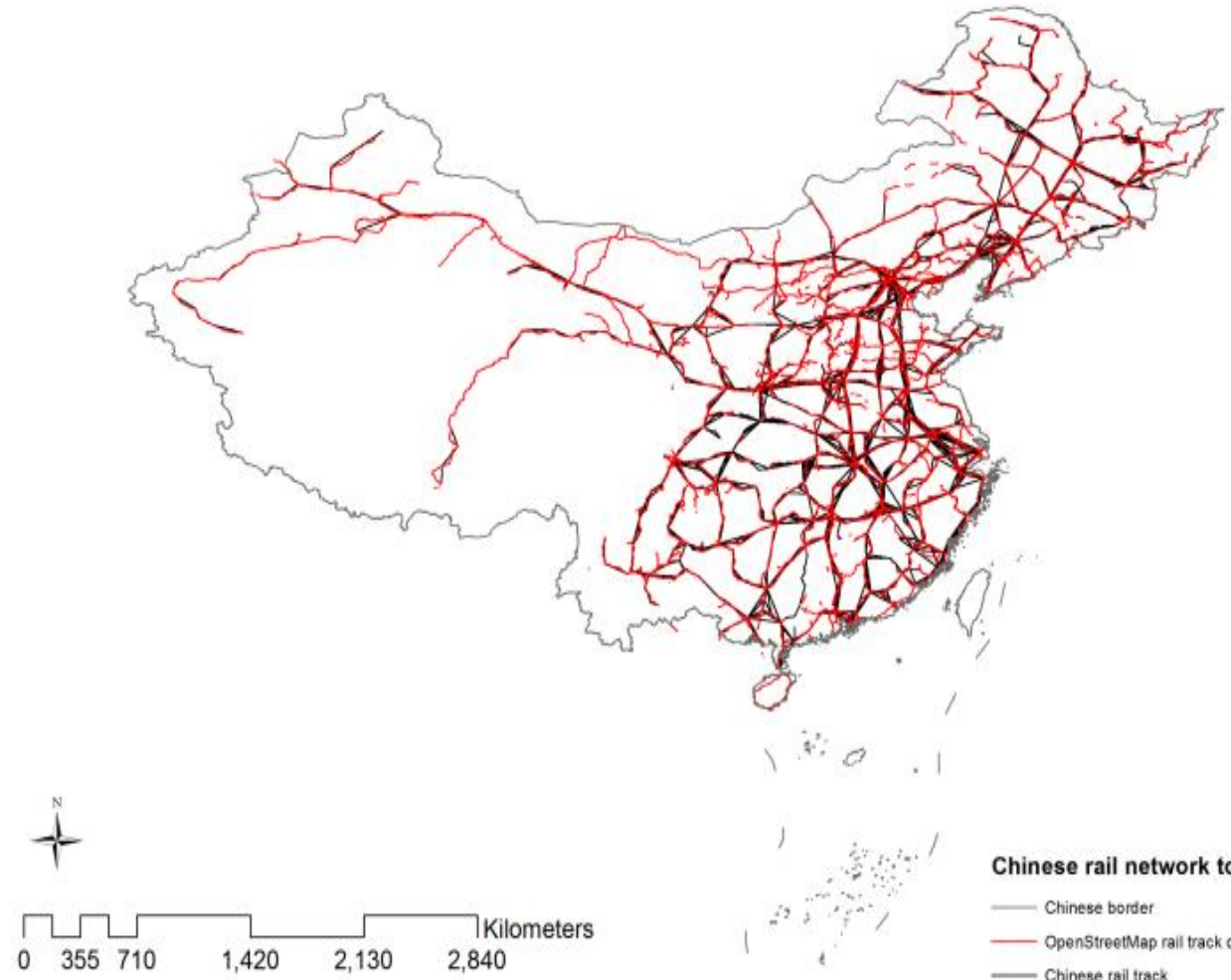

Chinese rail network topology

- Chinese border

- OpenStreetMap rail track data

Figure 4. Verification of artificially built topological Chinese rail network with the

Once we build the railway topological network, we assign passenger numbers over track paths. For each route, we record the stations it passes, for example, route "1" goes through stations A - B - F - E - D and route "2" goes through stations A -

$331 \mathrm{~B}-\mathrm{C}-\mathrm{D}$ (see Figure 5). We also note the number of passengers the train carries.

332 For instance, Electric Multiple Units (EMUs) often take 915 passengers (please refer 333 to Appendix A for a full list of carrying capacity for different types of train). Given 334 that the carrying capacity is similar for all types of trains, we restrict our analysis to 335 using the average passengers per route i.e. 1062 for allocating users to rail tracks. 336 Assuming the trains are operating at full capacity, we aggregate the total flow of 337 passengers through each track between any two stations during a three day period: in 338 Figure 5, the total number of passengers for the track between stations A and B is 116 $339+118=234$. 


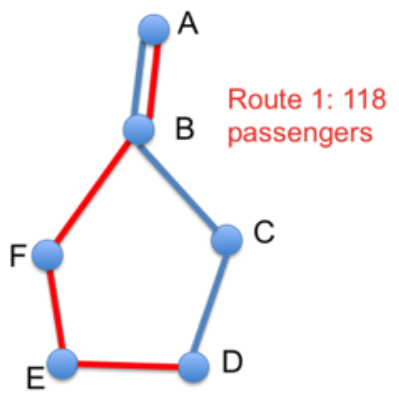

Figure 5. Calculation of total passengers through track A - B during any three-day period Building the topological railway network based on national train timetables provides us with information on the train frequency on each track. With supplementary data on the passenger capacity of each train, we are able to assign a total number of daily users to each track.

\subsubsection{Electricity sub-sector}

For the electricity sub-sector, we allocate users to each plant based on data on actual output per plant and electricity consumption per capita for the particular province in which the plant is located. The number of users per power plant, $C_{p}$, is given by the equation:

$$
C_{p}=P_{a} * \frac{E_{p, a}}{D_{a}}
$$

where $E_{p, a}$ is the energy output in megawatt-hours per year for power plant $p$ in a particular province $a ; D_{a}$ is the electricity consumption (in megawatt per hour) of province $a$; and $P_{a}$ is the population of province $a$.

We also consider the possible number of users missing from the analysis for each province. We do this by adding the total number of users, $C_{p, a}$, allocated for all power plants within province $a$ and comparing $C_{p, a}$ with the aggregate population for province $a$. The aggregate number of users missing, $M_{a}$, for province $a$ is given by the equation: 


$$
M_{a}=P_{a}-\sum_{i=1}^{p} C_{p, a}
$$

In reality, the number of users missing in provinces will vary enormously depending on the output capacity of the province. In fact, the aggregate number of users for some provinces should exceed the total population whereas for other provinces, it should fall below the population. This is owing to the fact that some provinces are "surplus" producing states that produce more electricity than they consume, whereas others are "deficit" states that produce less electricity than they consume. Figure 6 depicts these "surplus" and "deficit" provinces in blue and red respectively; we may assume that electricity is flowing from the blue provinces to the red through high voltage transmission lines.

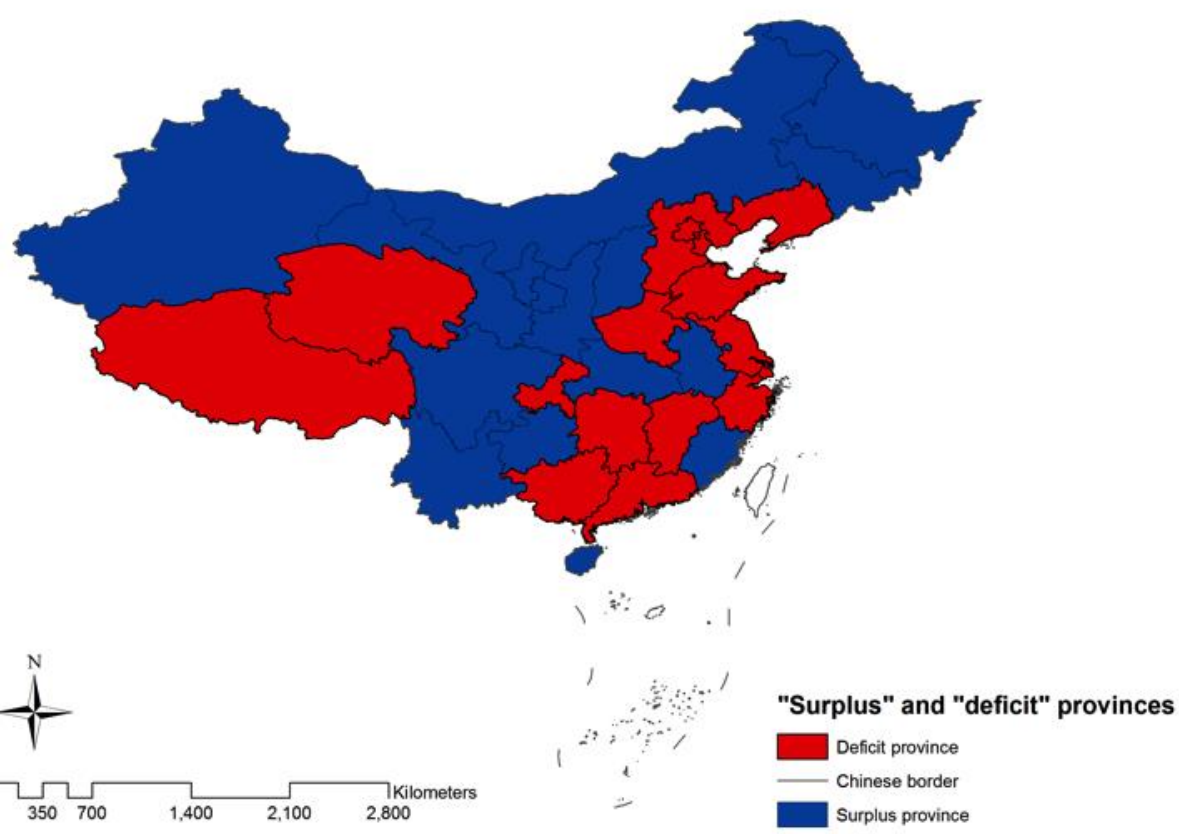

Figure 6. Electricity production and consumption "surplus" and "deficit" province comparisons. Provinces in "blue" are those that produce more than they consume whereas "red" provinces consume more than they produce. 
For the wastewater sub-sector, we take a similar approach with user allocation as we did to the electricity sub-sector except for the scale, which is at county-level. In some cases, we remove some of the wastewater treatment plants

393 from our full database as we do not have data on volume treated; in other cases, many plants have not been operationalised. Our analysis is based on a reduced sample of 1,680 plants as opposed to the full database of 2,743. We define the number of users, $C_{w}$, per waste treatment plant as:

397

$$
C_{w}=P_{b} * \frac{V_{w, b}}{V_{b}}
$$

where $V_{w, b}$ is the daily volume treated in $10,000 \mathrm{~m}^{3}$ for waste treatment plant $w$ in county $b ; V_{b}$ is the total waste water treated for county $b$; and $P_{b}$ is the population of county $b . V_{b}$ is calculated by equation (1) as shown below, where we aggregate all the waste water treated in any county $b$ :

$$
V_{b}=\sum_{k=1}^{w} V_{w, b}
$$

406

\subsection{Exposure and hotspot analysis}

408

Since the aim of the paper is to provide insights into the locations of critical

410 infrastructure at risk to flooding and drought impacts both on a broad and local 411 scale, we need to translate the exposure of those users who have only been

412 allocated on a local level to an exposure understanding on a broad level. The 413 concept of "hotspots" is particularly useful because it provides a visual 414 representation of exposure aided by a geo-spatial representation of "priority areas" 415 for planners to focus on.

We apply the Kernel density estimator (KDE) to derive "hotspots" for the 418 locations of critical infrastructure assets and networks. A KDE is a non-parametric 
419 statistical method for estimating the density of data. Here we apply the KDE 420 spatially, using the number of users dependent on an asset as our data. This way, a spatially continuous surface is constructed. The KDE is formally defined as:

$$
g\left(x_{i}\right)=\sum_{j=1}^{n}\left\{\left[P_{j}\right] \frac{1}{\pi h^{2}} K\left(\frac{e_{i j}}{h}\right)\right\}
$$

423 428

430

431

432

where $g\left(x_{i}\right)$ is the density at lattice location $x_{i}$ (individual cells), $P_{j}$ is the user demand associated with asset $j, h$ is the bandwidth of the density estimation (search radius) and $K\left(\frac{e_{\mathrm{i} j}}{h}\right)$ is the kernel applied to point $i$ that employs the distance $e_{i j} \forall j \leq h$. The kernel function employed in this study was a Gaussian:

$$
K\left(\frac{e_{i j}}{h}\right)=\left\{\frac{1}{\sqrt{2 \pi}} \exp \left(-\frac{e_{i j}^{2}}{2 h^{2}}\right)\right\}
$$

\subsubsection{Applying the KDE in China}

For all Chinese infrastructure sub-sectors, we construct the same size spatial lattice, which contains individual infrastructure assets at which KDE is performed. The size of each cell within the lattice is set as the default value, which is based on the extent of the chosen spatial reference and is calculated as the shorter of the width or height of the output extent in the output spatial reference, divided by 250 . This is based on an optimisation model within ArcGIS given the size of the lattices. Our chosen spatial reference is the "Asian_North_Albers_Equal_Area_Conic" in GIS and we transform it to the "GCS_China_Geodetic_Coordinate_System_2000" geographical coordinate system to minimise distortion. In addition, we use the same search radius $(200,000 \mathrm{~km})$ for all the infrastructure sub-sectors to obtain a consistent comparison among different hotspots. We conduct sensitivity analysis and find that the search radius $200,000 \mathrm{~km}$ provides the clearest visualisation of the results. 


\subsubsection{Disruption calculations}

447

448

449

450

451

452

453

454

455

456

457

458

459

460

461

462

463

464

465

466

467

468

469

470

471

472

473

474

475

For all assets except rail tracks, our hotspot analysis is based on the number of users allocated to each asset. To calculate the potential disruption should assets fail after flooding/drought event(s), we classify five categories of hotspots (Jenks Natural Breaks Classification in GIS) and locate the number of users within the top two categories as concentrations of exceptional vulnerability.

With regard to the tracks for the rail sub-sector, our hotspot analysis is not solely based on users allocated to the tracks. Rather, it is based on the total potential disruption for each track, $D_{t}$. For any three-day period, we calculate $D_{t}$ by multiplying train frequency for each track, $f_{t}$, with the number of passengers for each track $P_{t} . f_{t}$ is the number of routes (i.e. train frequency) that each path track takes, for example, the $f_{t}$ for track $\mathrm{A}-\mathrm{B}$ is two in Figure 3. Formally, $D_{t}$ is defined as:

$$
D_{t}=\sum f_{t} \times P_{t}
$$

Once users have been allocated, we standardise the time-scale so that users are allocated to all infrastructure assets on a yearly basis. For instance, the daily passenger freight for all rail stations is $1,205,000$; therefore the yearly users at risk are $1,205,000 * 365$ days in a year: $439,825,000$. The three-day passenger freight for rail tracks is 913,320 ; thus the number of yearly passengers at risk is $913,320 *$ (365/3): 111,120,600.

\subsection{Impose flood/drought hazard maps on the hot-spot analysis}

Lastly, we impose flood/drought hazard maps from the CaMa-Flood model and the Atlas of Natural Disaster Risk of China onto our hotspot analyses (Yamazaki et al. 2011; Shi 2011; Fang 2011). This provides us with a spatial understanding of how infrastructure hotspots, i.e. where users are concentrated, might be exposed to flooding and drought impacts. 


\subsubsection{Method for assessing the flood hazard and risk}

477

478

479

480

481

482

483

484

485

486

487

488

489

490

491

492

493

494

495

496

497

498

499

500

501

502

503

504

505

506

507

Flood risk is commonly defined as the product of the probability of flooding and the consequential damage, summed over all possible flood events (Hall et al. 2005). The probability of flooding for a national-scale flooding risk map is typically derived from some hydrological modelling based on meteorological data or simulation, analyses of extreme value statistics that estimate the severity floods at different return periods, and inundation modelling that estimates flooding depths for a given geographical unit (Ward et al. 2013). The consequential damage is conventionally evaluated by some economic impact modelling, for instance, by adopting indicators that show affected population, GDP, and/or exposed urban asset values (Ibid).

In this study, we make use of a global river routing model called the Catchment-Based Macro-scale Floodplain (CaMa-Flood) model to prepare the flood hazard map (Yamazaki et al. 2011). Briefly, the CaMa-Flood routes the runoff input simulated by a land surface model into the oceans or lakes along a prescribed river network. It calculates river channel storage, floodplain storage, river discharge, river water depth and inundated area for each grid-cell at a spatial resolution of $0.25^{\circ} \times 0.25^{\circ}$. A recently developed Global Width Database for Large Rivers (GWD-LR) is also incorporated into it (Yamazaki et al. 2014). Following Hirabayashi and colleagues, we drive the CaMa-Flood model using the daily runoff (1979-2010) generated by the Minimal Advanced Treatment of a Land Surface Interaction Runoff (MATSIRO) (Hirabayashi et al. 2013; Takata et al. 2003). We note that the MATSIRO model was forced by observations and reanalysis climate data (Kim et al. 2009).

Detailed description with reasoning and technical aspect of flood inundation map preparation using the CaMa-Flood model will be available in an upcoming paper on flood defence benefit and risk at the global scale (Lim et al. n.d.; in preparation). Here, we briefly describe the overall process of obtaining our flood inundation map. To prepare a flood inundation map of a specific magnitude, we 
508 select the Gumbel distribution (Gumbel, 1941) for its simplicity and demonstrated 509 consistency with general extreme value statistics (Dankers \& Feyen 2008). We use 510 annual maxima of river water depth (from CaMa-Flood) to perform extreme value 511 estimation at each grid-cell. Based on the digital elevation models (SRTM3 DEM 512 between $60^{\circ} \mathrm{N}$ and $60^{\circ} \mathrm{S}$; GTOPO30 above $60^{\circ} \mathrm{N}$ (Hirabayashi et al 2013), we 513 downscale and prepare the flood inundation map for a return period of 100 years at 514 high spatial resolution $\left(2.5^{\prime} \times 2.5^{\prime}\right)$ to support the analysis of this manuscript. This 515 inundation map is used as the base flood hazard map and is further downscaled for 516 the infrastructure hotspot analysis in Section 3.4.3.

\subsubsection{Method for assessing drought hazard in China}

Drought is the result of many composite factors such as high temperatures, high winds, low relative humidity, timing and characteristics of rain (Mishra \& Singh 2010). Capturing drought risk of a probabilistic nature is difficult because of these complex factors involved; therefore several indices have been developed that characterise different aspects of drought risks. Prominent examples of drought indices include the Standardised Precipitation Index (SPI), the Palmer Drought Severity Index (PDSI), the Crop Moisture Index, the Surface Water Supply Index, the Vegetation Condition Index, and the Standardised Runoff Index (Ibid). Some indices, such as the SPI, only focus on precipitation, whereas others such as PDSI may incorporate variation in temperature, soil moisture, reservoir storage, streamflow, and snow pack (Ibid). anomaly percentage of precipitation, $H_{s}$, and the ranking of the sensitivity of land use, $V_{s}$, towards $H_{s}$ in a 1-km grid (Shi, 2011). The equation is shown below:

$$
R_{L}=H_{S} \times V_{S}
$$




$$
H_{s}=\frac{|P a|-P a \min }{P a \max -P a \min } \times 100 \%
$$

539 where $P a=\frac{P-\bar{P}}{\bar{P}} \times 100 \% . P$ is the precipitation volume in any particular

540 time period. $\bar{P}$ is the average precipitation volume in the time period concerned.

541

542 Six types of land use are considered, namely: arable land, grassland, 543 woodland, urban, water areas, and unused land. Larger values of $H_{s}$ indicate higher 544 sensitivity of $\operatorname{land}^{5}$ (Shi 2011). It is important to note that this drought assessment is 545 hydrological in the sense that we identify high-risk areas when there is water 546 deficiency. However, the way in which water infrastructure is affected by and/or 547 influences water scarcity is not captured. Validation of the drought hazard map is 548 shown in Appendix E.

549

\subsubsection{Integrating flooding and drought hazard maps with infrastructure} hotspot analyses

552

In order to derive an aggregate understanding of how infrastructure hotspots are subject to flooding and drought impacts, we impose our hotspot analyses onto the flooding and drought hazard maps separately. For flooding, we look at all infrastructure sub-sectors. However, we restrict our study to the electricity subsector only for drought because, compared to electricity where a lack of water supply may result in suspension of energy production, drought does not affect the other sub-sectors such as rail and aviation as much. In Table 3, we demonstrate how we integrate flood map with rail hotspot analyses. The same method is applied to all other infrastructure assets.

\footnotetext{
${ }^{5}$ For detailed drought methodology, please refer to the Atlas of Natural Disaster Risk of China (Shi 2011).
} 


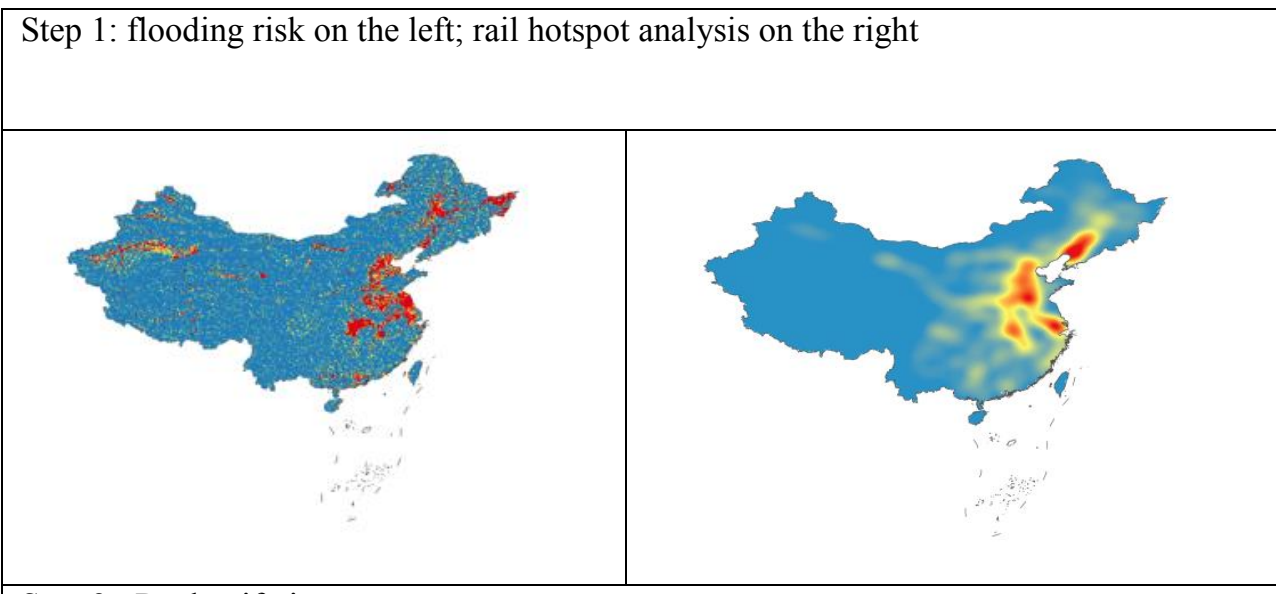

Step 2: Reclassify images

Integrate rasters with a common scale. We adopt the scale of 1 to 8 by increments of 1 , 8 being the most likely to be flooded or containing the highest concentrations of users.

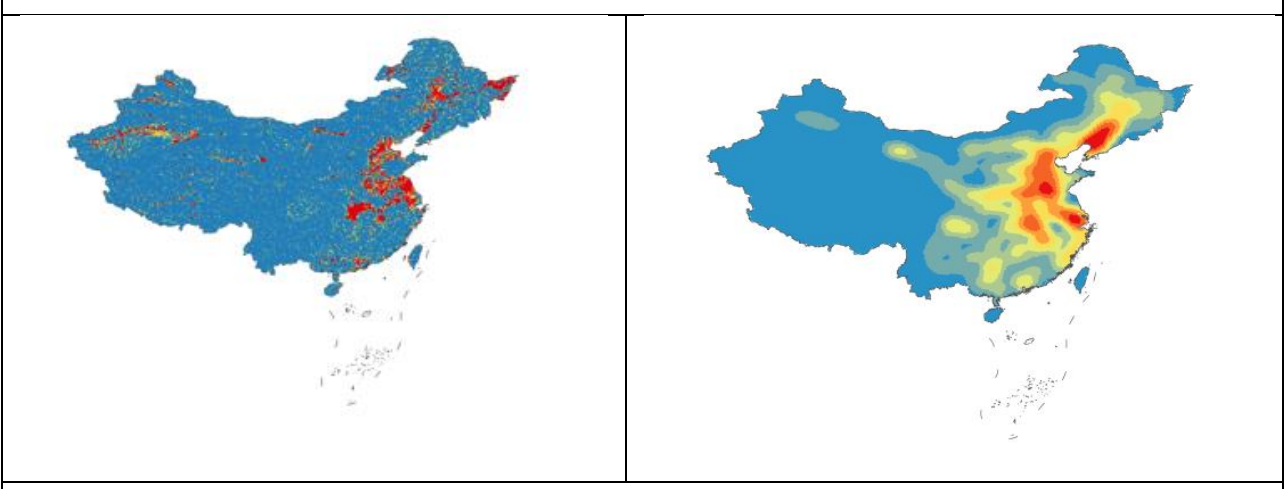

Step 3: Weighted overlay

Combining the two images provides us with an integrated map showing vulnerable areas according to both high flood risk and concentrations of users for the rail subsector.

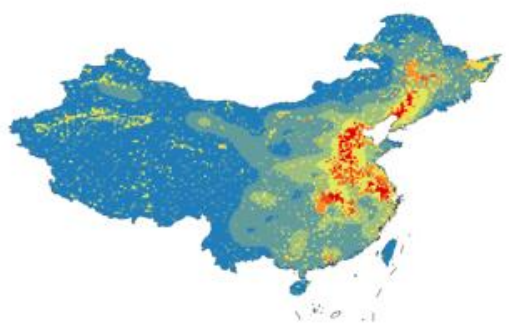




\section{Results}

573

574

Our results are divided into three main sections: (i) integrated spatial

575 analysis for both flooding and drought impacts in section 4.1; (ii) sector exposure to

576 flooding and drought impacts with respect to concentration of users, presented in

577 section 4.2; and (iii) infrastructure exposure both with respect to space and users,

578 but not considering flooding and drought impacts in section 4.3.

579

580

\subsection{Integrated analysis}

581

\subsubsection{Flooding and infrastructure hotspots overlaid}

582

583

The integrated analysis combines flooding risk analyses with infrastructure

vulnerability for sub-sectors including rail, aviation, shipping, electricity and

585 wastewater (refer to Figure 7). At a provincial level, Anhui, Beijing, Guangdong, Hebei, Henan, Jiangsu, Liaoning, Shandong, Shanghai, Tianjin, Zhejiang ${ }^{6}$ exposed to flooding risks; at a city level, 66 cities are highly exposed (refer to Appendix B).

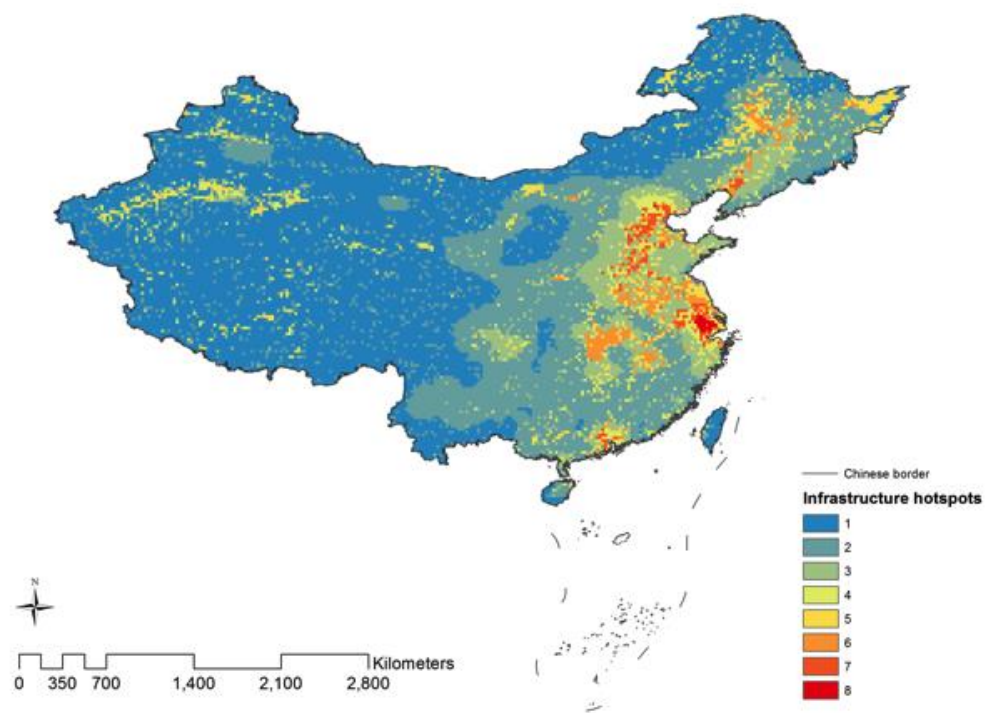

Figure 7. Infrastructure vulnerability (rail, aviation, shipping, electricity and wastewater sub-sectors) combined with flooding hazard.

\footnotetext{
${ }^{6}$ Exceptionally exposed is defined as provinces that are located in areas where their infrastructure hotspot values are either 7 or 8 .
} 


\subsubsection{Drought hazard and infrastructure hotspots overlaid with the} electricity sub-sector

597 Jiangsu are areas that are especially vulnerable. At a city level, the 99 cities that are at high drought exposure are listed in Appendix C.

599

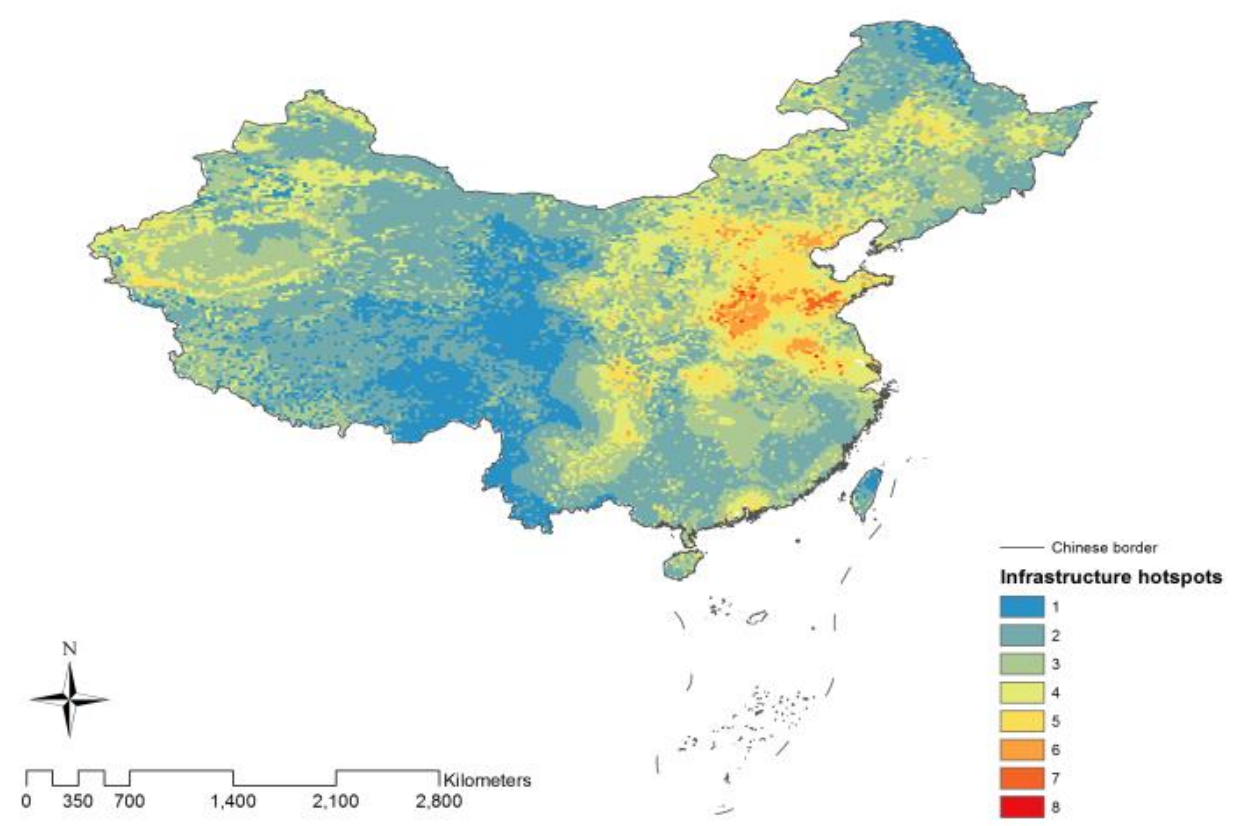

600

601

602

603

604

605

606

607

608

609

610
Figure 8. Infrastructure vulnerability for the electricity sub-sector combined with integrated drought hazard map.

\subsection{Sub-sector vulnerability to flooding and drought risks}

In terms of concentration of users, Tables 4 and 5 show that although most infrastructure assets are not situated in high flooding risk and drought hazard zones, the number of potentially vulnerable users is still high. For flood risk level 8 , the average number of vulnerable users for all infrastructure sub-sectors stands at $144,306,112$; for drought risk level 8 in the electricity sub-sector, it stands at 
$6116,279,536$. Among all sub-sectors, the most vulnerable to flooding risks are 612 electricity and wastewater (20\% and $14 \%$ of the total respectively). 


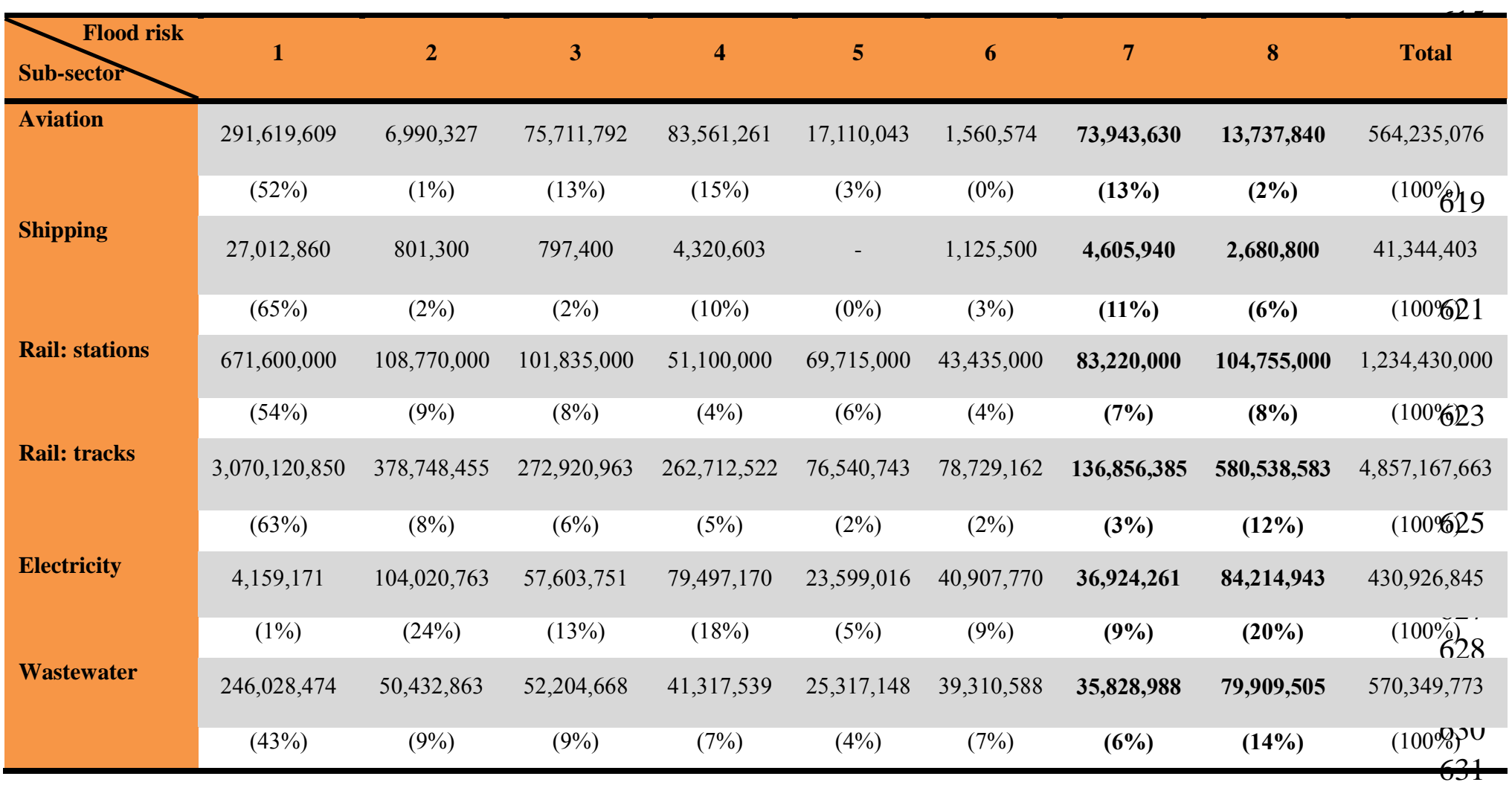

*We standardise user numbers on a yearly basis. For train stations, we multiply daily passenger numbers by 365 days.

633 For rail tracks, we calculate the percentage of rail tracks exposed to different levels of flood risks, and multiply this by the total number of passengers per year?

\footnotetext{
${ }^{7}$ Note that the number for rail track is very large. This is because it's an estimate of potential disruption which includes the passenger numbers and frequency. For details, please refer to Section 3.3.2.
} 
634 Table 5. Number of users at various grades of drought risks for the electricity sub-sector

\begin{tabular}{lcccccccccc}
\hline \multicolumn{1}{c}{ Drought risk } & $\mathbf{1}$ & $\mathbf{2}$ & $\mathbf{3}$ & $\mathbf{4}$ & $\mathbf{5}$ & $\mathbf{6}$ & $\mathbf{7}$ & $\mathbf{8}$ & Total \\
Sub-sector & & & & & & & \\
\hline Electricity & $579,710,487$ & $89,543,435$ & $97,168,568$ & $104,493,014$ & $58,790,810$ & $37,893,280$ & $\mathbf{6 , 7 9 8 , 6 7 2}$ & $\mathbf{6 , 2 7 9 , 5 3 6}$ & $977,962,351$ \\
& $(59 \%)$ & $(9 \%)$ & $(10 \%)$ & $(11 \%)$ & $(6 \%)$ & $(4 \%)$ & $(\mathbf{1 \% )}$ & $(\mathbf{1 \%})$ & $(100 \%)$ \\
\hline
\end{tabular}

635

*We standardise user numbers on a yearly basis. 


\subsection{Infrastructure vulnerability}

\subsubsection{Overall infrastructure exposure}

638

639

Not taking into account flooding or drought hazards, infrastructure exposure

640 alone is concentrated around the south of Beijing, northern Tianjin, southern

641 Jiangsu, Shanghai, and northern Zhejiang provinces (Figure 9). The 18 cities that 642 are exceptionally vulnerable are listed in Appendix D.

643

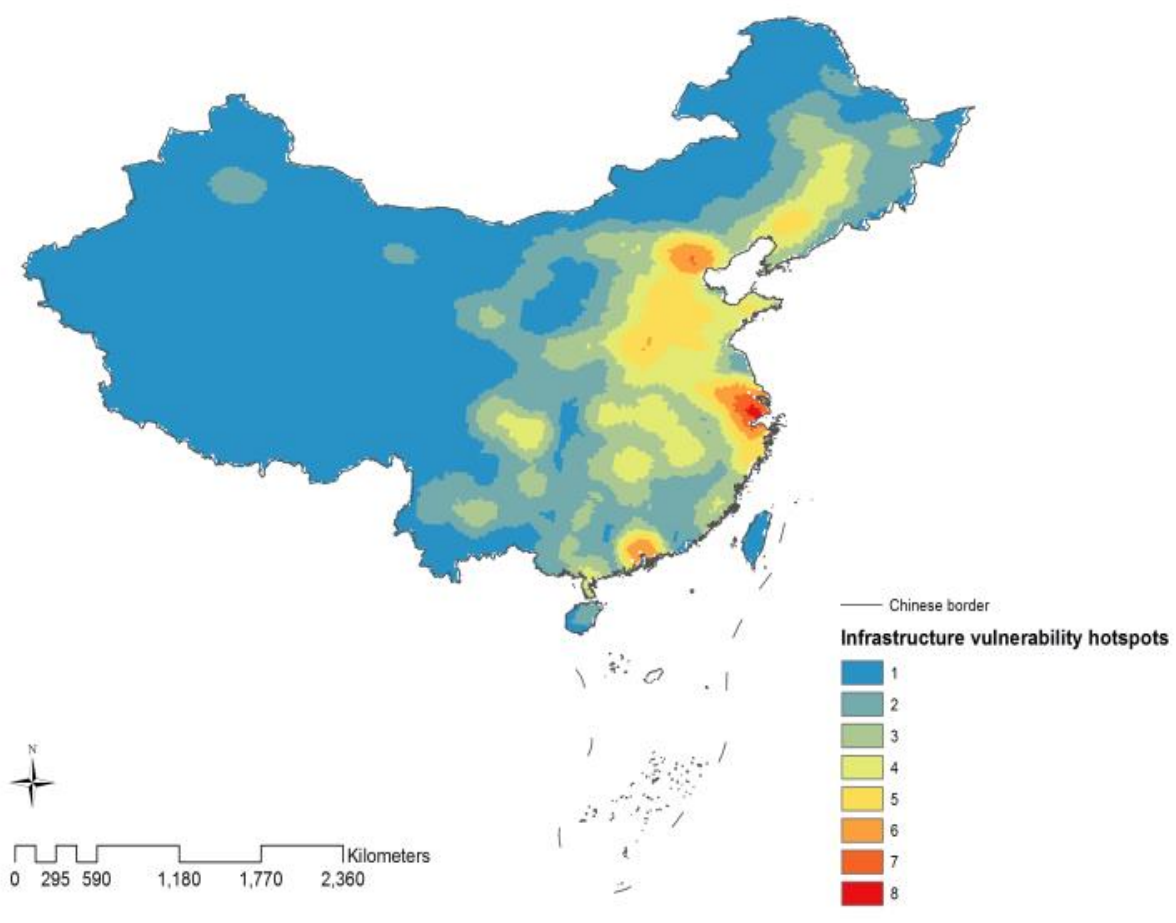

644

645

Figure 9. Composite infrastructure vulnerability using the "Overlay" tool (rail, aviation, shipping, electricity and wastewater sub-sectors)

647

648

\subsubsection{Sub-sector exposure}

649

650

One can also observe infrastructure exposure separately by looking at different sub-sectors (Figures 10-13). For the rail sub-sector, the analyses for rail stations (Figure 10, left) and rail tracks (Figure 10, right) reflect similar hotspots in

653 that Beijing is highly vulnerable. However, using train timetable information

654 represents a better understanding of vulnerable hotspots such as Shanghai, Hubei, 
655 Shandong and Henan, through which substantial traffic passes, are also identified.

656 The results for aviation (Figure 11, left) and shipping (Figure 11, right) are not 657 surprising - the airports and ports that take the most passengers are identified as 658 vulnerable hotspots. For the electricity sub-sector, north Henan, south Shanxi, south 659 Jiangsu, Anhui, Shanghai, west Hubei, south Guangdong are vulnerable provinces 660 (Figure 12, left). In addition, we successfully identify the surplus producing 661 provinces in Figure 12 (right), highlighted in green. For wastewater, south Hebei, 662 coastal Shandong, eastern Henan, northwest Anhui, south Jiangsu, and north 663 Zhejiang are the most vulnerable provinces (Figure 13).

664

665

666

667

668

669

670

671

672

673

674
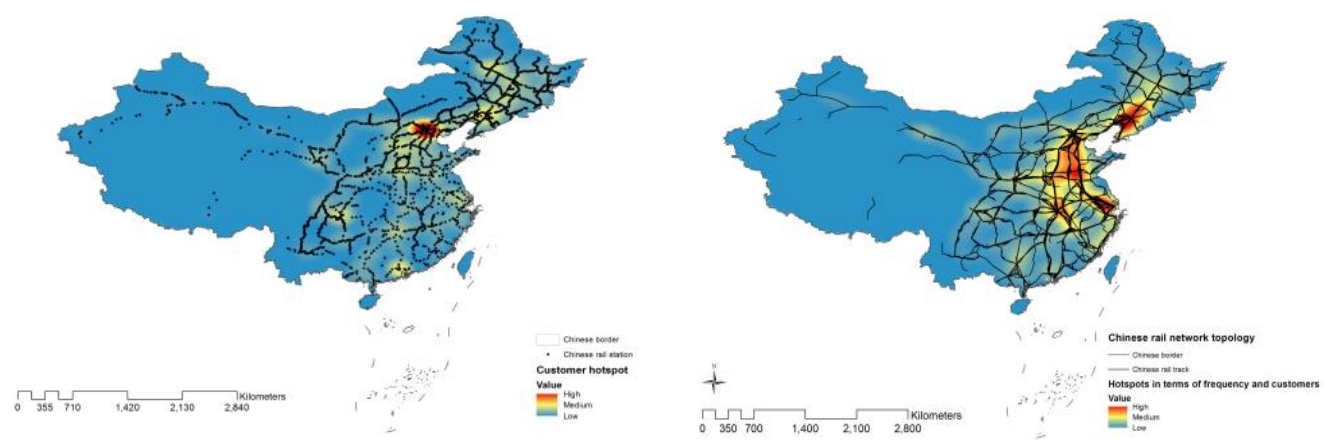

Figure 10. Rail stations user hotspot analysis at 200,000 km search radius (Left). Rail track user hotspot analysis at 200,000 km search radius, based on use frequency of rail tracks and number of users (Right)
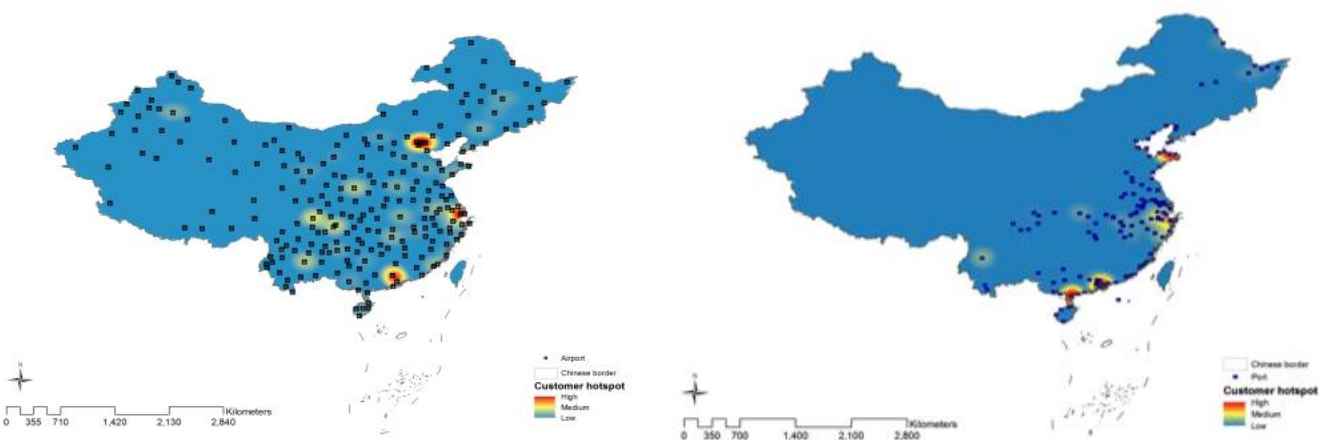

Figure 11. Airport user hotspot analysis at 200,000km search radius (Left). Port user hotspot analysis at 200,000km search radius (Right) 

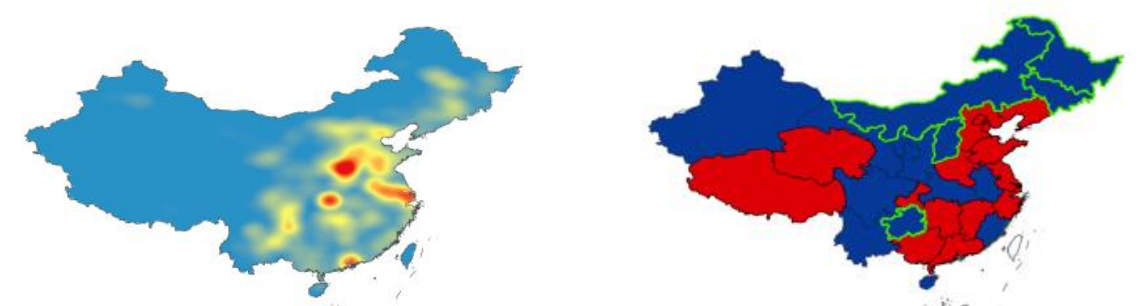

676 Figure 12. Power stations user hotspot analysis at 200,000km search radius (Left).
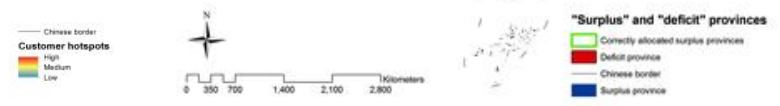

677 Successfully allocated five provinces that are "surplus" provinces, highlighted in 678 green (Right).

679

680

681

682

683

684

685

686

687

688

689

690

691

692

693

694

695

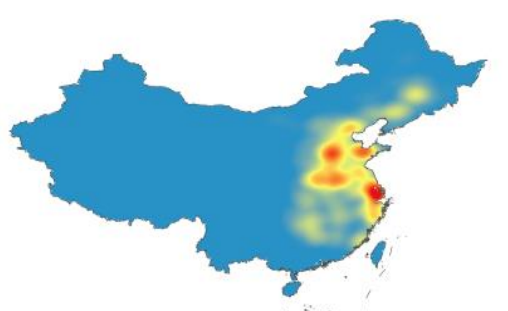

$+$

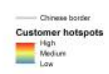

Figure 13. Wastewater subsector hotspot analysis at $200,000 \mathrm{~km}$ search radius

The potential number of users affected is very high for the rail, electricity and wastewater sub-sectors, as shown in Table 6. However, it is important to note that our database for shipping is incomplete; therefore the real exposure may be significantly higher than that presented here. The results exhibited in this section do not include any hazards and can be used for further analysis for other disasters such as landslides.

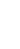


Table 6: Potential number of users affected in different infrastructure assets in a year

697

\begin{tabular}{|l|l|l|}
\hline Infrastructure assets & Number of users & $\begin{array}{l}\text { Percentage of total } \\
\text { population }(\%)\end{array}$ \\
\hline Rail stations & $439,825,000$ & 33.0 \\
\hline Rail tracks & $111,120,600$ & 8.34 \\
\hline Port & $1,529,350$ & 1.15 \\
\hline Airport & $321,766,557$ & 24.2 \\
\hline Electricity & $451,202,612$ & 33.9 \\
\hline Wastewater & $315,478,372$ & 23.7 \\
\hline
\end{tabular}

698

\section{Discussion}

699

The purpose of this study is to understand how the Chinese infrastructure system is exposed to flooding and drought impacts. In particular, we seek to provide insights into the locations of critical infrastructure at risk to flooding and drought impacts on a broad scale, and estimate the potential number of users affected on the local scale should infrastructure assets fail owing to one or a series of flooding/drought event(s).

Several assumptions are required in order to locate critical infrastructures. First, we assume an infrastructure system consisting of five sectors - energy, transport, water, waste and ICT. Although this taxonomy approach is necessary to help us restrict the scope of our analysis, it inevitably leaves some infrastructure assets such as buildings yet to be studied.

714 passenger numbers to individual rail tracks. This is a valid assumption, as most

715 trains in China are in fact operating beyond their designed capacities. According to

716 Xinhua News, the official news channel for China, the national average passenger 717 attendance is $133 \%$ and $120 \%$ for rail services (Yin 2010). Therefore our 718 assumption of $100 \%$ is reasonable and in fact represents an underestimate of the real exposure of rail assets to flooding/drought hazards. 
Third, owing to very limited data on national-scale transmission grids in

721 China, we assume that generation capacity in a specific region directly supplies a specific number of people in that region. This is a limitation in our work because we are not able to take into account energy flows between regions and our results consider hazard impact on generation and not transmission. However, with approximately $20 \%$ of electricity produced nationally is being transferred across provinces, we believe our analysis focused on generation impact still represents the reality reasonably (State Grid Energy Research Institute 2014). Future research will require a better understanding of the transmission networks given China is building many "Ultra High Voltage" transmission networks that are able to transfer electricity across three or four provinces at a time (Ibid).

In addition to the assumptions discussed above, we use a global flooding risk model developed to prepare the flood hazard map (Yamazaki et al. 2011). This is owing to the lack of a national-level flooding risk assessment with hydrological modelling at the time of this study. The limitations of using global flooding risk models have been discussed extensively by Ward et al (2015). Future work could look into comparing the risk map with alternatives such as the global flood risk map by Ward and others, or the Pappenberger and others' global flood hazard map by the Hydrology and Earth System Science, or the national flooding risks mapping efforts by the Chinese Ministry of Water Resources ${ }^{8}$ (Pappenberger et al. 2012; Ward et al. 2013). In addition, the flood calculations do not account for flood defence because of poor documentation of data for China and elsewhere (e.g., see Supplementary Table 2 in Jongman et al. 2014). More work is required to understand how flood infrastructure changes flooding and drought risks on the national scale.

Despite the aforementioned assumptions and limitations, our results inform policy making by identifying locations of critical infrastructures exposed to

749 flooding/drought impacts on the national-level. We find that at a provincial level,

\footnotetext{
8 Personal communication with the Chinese Ministry of Water Resources indicated that a national-scale flooding risk map should be available by 2017.
} 
750 Anhui, Beijing, Guangdong, Hebei, Henan, Jiangsu, Liaoning, Shandong, 751 Shanghai, Tianjin, Zhejiang; at a city level, 66 cities are at high risk. This is for 752 sub-sectors including rail, aviation, shipping, electricity and wastewater. For 753 drought, we demonstrate that southern border of Inner Mongolia, Shandong, 754 Shanxi, Hebei, north Henan, Beijing, Tianjin, southwest of Jiangsu are areas that 755 are especially vulnerable. At a city level, 99 cities are at high risk.

The above exposed regions are to some extent not surprising because they are all highly urbanised and have experienced exponential growth in infrastructure assets. To see this, we overlay the infrastructure hotspots with a map of the urbanisation extent in 2012 using DMSP-OLS night time light data (NOAA 2015).

761 The urban extent is used as a reference against the hotspot analysis. In fact, Figure

76214 demonstrates that our infrastructure hotspots capture the urban areas very well 763 all our red and yellow hotspots are located in areas where the lighted regions are.

764 The exception of the area highlighted in the orange circle may be caused by a lack 765 of infrastructure data. Interestingly, our hotspot map highlights the south coast (the 766 green oval-shaped circle in Figure 14) as highly exposed in terms of critical 767 infrastructures. The urban extent map is unable to reveal this insight because it 768 relies on streetlights being captured by satellites i.e. if the streetlights are spread 769 across a large area, the night time map will not be able to identify urban areas that 770 have many critical infrastructures. Thus, our analysis provides additional insights to conventional exposure studies that solemnly rely on population or urban data. 


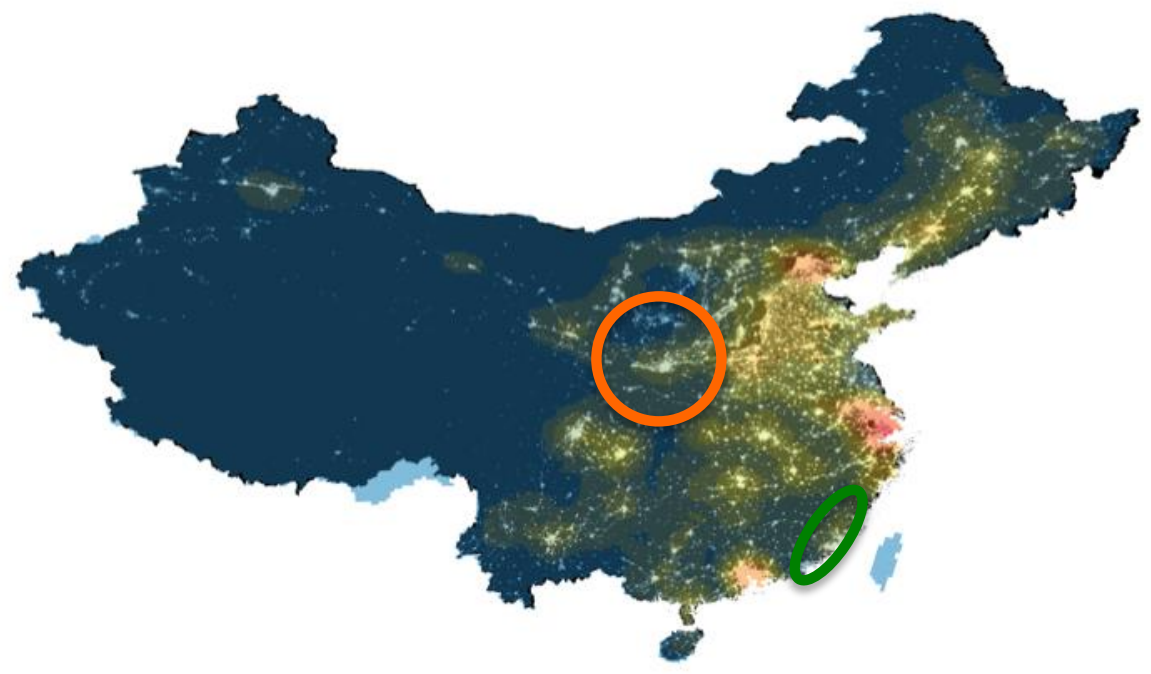

774 Figure 14. Urbanisation extent using DMSP-OLS night time light data from $2012^{9}$

In terms of policy implications, our analysis provides scientific evidence for mandating disaster risk reduction in China as we demonstrate the scale of the potential number of people affected. For flooding, the average number of vulnerable users for the above sub-sectors stands at 103 million and the most

780 vulnerable are electricity and wastewater ( $20 \%$ and $14 \%$ of the total respectively).

781 For drought risks, the number of exceptionally vulnerable users for the electricity 782 sub-sector is 6.5 million. As such, the work could help regional leaders be 783 informed of their potential vulnerabilities and exposure.

\section{Conclusions}

786

Infrastructure growth has not only contributed enormously towards China's growth, but also hindered it during periods of failures when natural disasters such as flooding and drought have occurred. Given that infrastructure development remains a top priority for China's government and climate change is projected to

\footnotetext{
${ }^{9}$ Two national boundaries do not match because one is extracted from the Atlas of Natural Disasters in China which includes Taiwan and Arunachal Pradesh; the other is from US National Oceanic and Atmospheric Administration.
} 
791

792

793

794

795

796

797

798

799

800

801

802

803

804

805

806

807

808

809

810

811

812

813

814

815

816

817

818

819

820

821

822

13

aggravate the impacts of natural disasters, understanding the exposure and vulnerability of these assets has become increasingly important.

Unfortunately, it is not easy to study the exposure and vulnerability of the infrastructure system at a national scale in China for two main reasons. First, data on infrastructure assets are very limited. Even when they do exist, often they are in Chinese and spread across different data sources such as national/regional/local statistical yearbooks. This is perhaps why existing literature has been restricted to city-scale analyses and broader scale studies tend to be focused on one sector only. Second, the infrastructure system consists of many sectors that make comparisons of exposure and vulnerability between them difficult.

Our work has addressed the former challenge by taking a first step to look at infrastructure exposure and vulnerability on the broad scale. To do this, we have built a database consisting of 10,561 nodes and 2,863 edges across three different infrastructure sectors and networks. We have developed a methodology that creates a common metric i.e. concentration of users based on empirical data where possible, which helps us compare vulnerability across different infrastructure sectors from a systems perspective despite the nature of disruption can vary among sectors. This approach could be used to study other natural disasters that are common in China, such as snowstorms and landslides.

As already discussed earlier, one limitation of this paper is that the results may not show all infrastructure hotpots because in some cases we have incomplete datasets on infrastructure assets. Therefore the results presented may be an underestimate of infrastructure exposure and vulnerability. In addition, although sufficient for a national assessment, the resolution for flooding and drought analyses is not high. Further, we are not able to capture inter-provincial electricity transfer for our electricity "hotspot" analysis, as we do not have data on nationalscale transmission networks. Further, we resort to using the results from a global flooding risk model as a national-scale study based on hydrological modelling is not available at the time of study. 
823 Despite the limitations, this work is useful for informing strategic 824 infrastructure planning and the methodology applied here can be transferred to 825 other geographical areas on the national-scale. Future work will attempt to look at 826 how this spatial exposure may change given further urbanisation and climate 827 change impacts.

828

\section{Acknowledgement}

830

This work was supported by the Asian Studies Centre, University of Oxford.

832 JWH and WHL acknowledge the Oxford Martin School for the financial support of 833 this study through the grant OMPORS.We thank Simon Abele at the Environmental 834 Change Institute (ECI), University of Oxford, for his contribution in assembling the 835 OpenStreetMap network dataset. We are also grateful to Dr. Raghav Pant for coding 836 the input from the flood results, Scott Thacker at the ECI and Valerie Bevan for 837 their comments during the development of the paper.

838

839 
APPENDIX A

841

842 Table 7: Route type and carrying capacity

\begin{tabular}{|l|l|}
\hline Category & $\begin{array}{l}\text { Carrying } \\
\text { Capacity } \\
\text { (Persons) }\end{array}$ \\
\hline Electric Multiple Unit (EMU) & 915 \\
\hline Ordinary Express & 1000 \\
\hline Temporary Trains & 1888 \\
\hline Intercity High Speed Rail & 560 \\
\hline Fast trains & $1062^{*}$ \\
\hline Direct Express & $1062^{*}$ \\
\hline Fast Express with Air Conditioning & 538 \\
\hline Ordinary Express with Air Conditioning & 1254 \\
\hline Express with Air Conditioning & 1288 \\
\hline High Speed Electric Multiple Unit & 1053 \\
\hline
\end{tabular}

843 *Data on fast and direct express trains are not available; therefore we calculate the average carrying 844 capacity based on the other types of trains.

845 


\section{Appendix B}

847

848 List of cities exposed to high flooding risks for all infrastructure sub-sectors (rail, 849 aviation, shipping, electricity and wastewater)

\begin{tabular}{|c|c|}
\hline City & Province \\
\hline Chaohu & Anhui \\
\hline Chuzhou & Anhui \\
\hline Hefei & Anhui \\
\hline Ma'anshan & Anhui \\
\hline Suzhou & Anhui \\
\hline Wuhu & Anhui \\
\hline Xuancheng & Anhui \\
\hline Beijing & Beijing \\
\hline Dongguan & Guangdong \\
\hline Foshan & Guangdong \\
\hline Guangzhou & Guangdong \\
\hline Huizhou & Guangdong \\
\hline Jiangmen & Guangdong \\
\hline Qingyuan & Guangdong \\
\hline Zhaoqing & Guangdong \\
\hline Zhongshan & Guangdong \\
\hline Zhuhai & Guangdong \\
\hline Baoding & Hebei \\
\hline Cangzhou & Hebei \\
\hline Handan & Hebei \\
\hline Hengshui & Hebei \\
\hline Langfang & Hebei \\
\hline Shijiazhuang & Hebei \\
\hline Tangshan & Hebei \\
\hline Xingtai & Hebei \\
\hline Anyang & Henan \\
\hline Hebi & Henan \\
\hline Jiaozuo & Henan \\
\hline Kaifeng & Henan \\
\hline
\end{tabular}




\begin{tabular}{l|l}
\hline Luohe & Henan \\
Puyang & Henan \\
Xinxiang & Henan \\
Xuchang & Henan \\
Zhengzhou & Henan \\
Zhoukou & Henan \\
Changzhou & Jiangsu \\
Nanjing & Jiangsu \\
Nantong & Jiangsu \\
Suzhou & Jiangsu \\
Taizhou & Jiangsu \\
Wuxi & Jiangsu \\
Xuzhou & Jiangsu \\
Yancheng & Jiangsu \\
Yangzhou & Jiangsu \\
Zhenjiang & Jiangsu \\
Anshan & Liaoning \\
Fuxin & Thanjin \\
Jinzhou & Liaoning \\
Liaoyang & Shandong \\
Panjin & Liaoning \\
Shenyang & Liaoning \\
Binzhou & Liaoning \\
Dezhou & Liaoning \\
Heze & Shandong \\
Jinan & Shandong \\
Jining & Shandong \\
Liaocheng \\
Linyi \\
Tai'an \\
Zaozhuang \\
Zibo & Shandong \\
\hline Shanghai & Shandong \\
\hline
\end{tabular}




\begin{tabular}{l|l}
\hline Hangzhou & Zhejiang \\
Huzhou & Zhejiang \\
Jiaxing & Zhejiang \\
Ningbo & Zhejiang \\
Shaoxing & Zhejiang \\
\hline
\end{tabular}

850

851 
852 Appendix C

853

854 List of cities exposed to high drought risks for the electricity sub-sector

\begin{tabular}{l|l}
\hline City & Province \\
\hline Weinan & Shaanxi \\
Bengbu & Anhui \\
Bozhou & Anhui \\
Chaohu & Anhui \\
Chuzhou & Anhui \\
Fuyang & Anhui \\
Hefei & Anhui \\
Huaibei & Anhui \\
Huainan & Anhui \\
Lu'an & Anhui \\
Ma'anshan & Anhui \\
Suzhou & Anhui \\
Wuhu & Anhui \\
Xuancheng & Anhui \\
Beijing & Beijing \\
Dongguan & Guangdong \\
Huizhou & Guangdong \\
Jiangmen & Guangdong \\
Yangiang & Guangdong \\
Bijie & Guizhou \\
Zunyi & Guizhou \\
Chengde & Hebei \\
Handan & Hebei \\
Langfang & Hebei \\
Qinhuangdao & Hebei \\
Shijiazhuang & Hebei \\
Xingtai & Hebshangiang \\
\hline
\end{tabular}




\begin{tabular}{|c|c|}
\hline Qitaihe & Heilongjiang \\
\hline Shuangyashan & Heilongjiang \\
\hline Anyang & Henan \\
\hline Hebi & Henan \\
\hline Jiaozuo & Henan \\
\hline Jiyuan shi & Henan \\
\hline Kaifeng & Henan \\
\hline Luohe & Henan \\
\hline Luoyang & Henan \\
\hline Nanyang & Henan \\
\hline Pingdingshan & Henan \\
\hline Puyang & Henan \\
\hline Sanmenxia & Henan \\
\hline Xinxiang & Henan \\
\hline Xinyang & Henan \\
\hline Xuchang & Henan \\
\hline Zhengzhou & Henan \\
\hline Zhoukou & Henan \\
\hline Zhumadian & Henan \\
\hline Jingmen & Hubei \\
\hline Suizhou Shi & Hubei \\
\hline Xiangfan & Hubei \\
\hline Yichang & Hubei \\
\hline Changde & Hunan \\
\hline Zhangjiajie & Hunan \\
\hline Changzhou & Jiangsu \\
\hline Huai'an & Jiangsu \\
\hline Nanjing & Jiangsu \\
\hline Wuxi & Jiangsu \\
\hline Yangzhou & Jiangsu \\
\hline Zhenjiang & Jiangsu \\
\hline Benxi & Liaoning \\
\hline Fushun & Liaoning \\
\hline Huludao & Liaoning \\
\hline
\end{tabular}




\begin{tabular}{|c|c|}
\hline Liaoyang & Liaoning \\
\hline Shenyang & Liaoning \\
\hline Hohhot & Nei Mongol \\
\hline Hulunbuir & Nei Mongol \\
\hline Ordos & Nei Mongol \\
\hline Ulaan Chab & Nei Mongol \\
\hline Yan'an & Shaanxi \\
\hline Yulin & Shaanxi \\
\hline Dezhou & Shandong \\
\hline Heze & Shandong \\
\hline Jinan & Shandong \\
\hline Jining & Shandong \\
\hline Laiwu & Shandong \\
\hline Liaocheng & Shandong \\
\hline Linyi & Shandong \\
\hline Qingdao & Shandong \\
\hline Rizhao & Shandong \\
\hline Tai'an & Shandong \\
\hline Weifang & Shandong \\
\hline Yantai & Shandong \\
\hline Zaozhuang & Shandong \\
\hline Zibo & Shandong \\
\hline Changzhi & Shanxi \\
\hline Datong & Shanxi \\
\hline Jincheng & Shanxi \\
\hline Jinzhong & Shanxi \\
\hline Linfen & Shanxi \\
\hline Luliang & Shanxi \\
\hline Shuozhou & Shanxi \\
\hline Taiyuan & Shanxi \\
\hline Xinzhou & Shanxi \\
\hline Yangquan & Shanxi \\
\hline Yuncheng & Shanxi \\
\hline Tianjin & Tianjin \\
\hline
\end{tabular}


Appendix D

856

857 List of cities that are exceptionally vulnerable in terms of infrastructure alone

\begin{tabular}{l|l}
\hline City & Province \\
\hline Xuancheng & Anhui \\
Beijing & Beijing \\
Baoding & Hebei \\
Langfang & Hebei \\
Tangshan & Hebei \\
Changzhou & Jiangsu \\
Nantong & Jiangsu \\
Suzhou & Jiangsu \\
Taizhou & Jiangsu \\
Wuxi & Jiangsu \\
Zhenjiang & Jiangsu \\
Shanghai & Shanghai \\
Tianjin & Tianjin \\
Hangzhou & Zhejiang \\
Huzhou & Zhejiang \\
Jiaxing & Zhejiang \\
Ningbo & Zhejiang \\
Shaoxing & Zhejiang \\
\hline
\end{tabular}

858

859 
Here we summarise the verification process as in the Atlas of Natural

863 Disaster Risk in China (Shi, 2011). Figure 15 shows the drought hazard map from

864 the Atlas. The red areas demonstrate higher potential for experiencing drought 865 events.

866

867

868

869

870

871

872

873

874

875

876

877

878

879

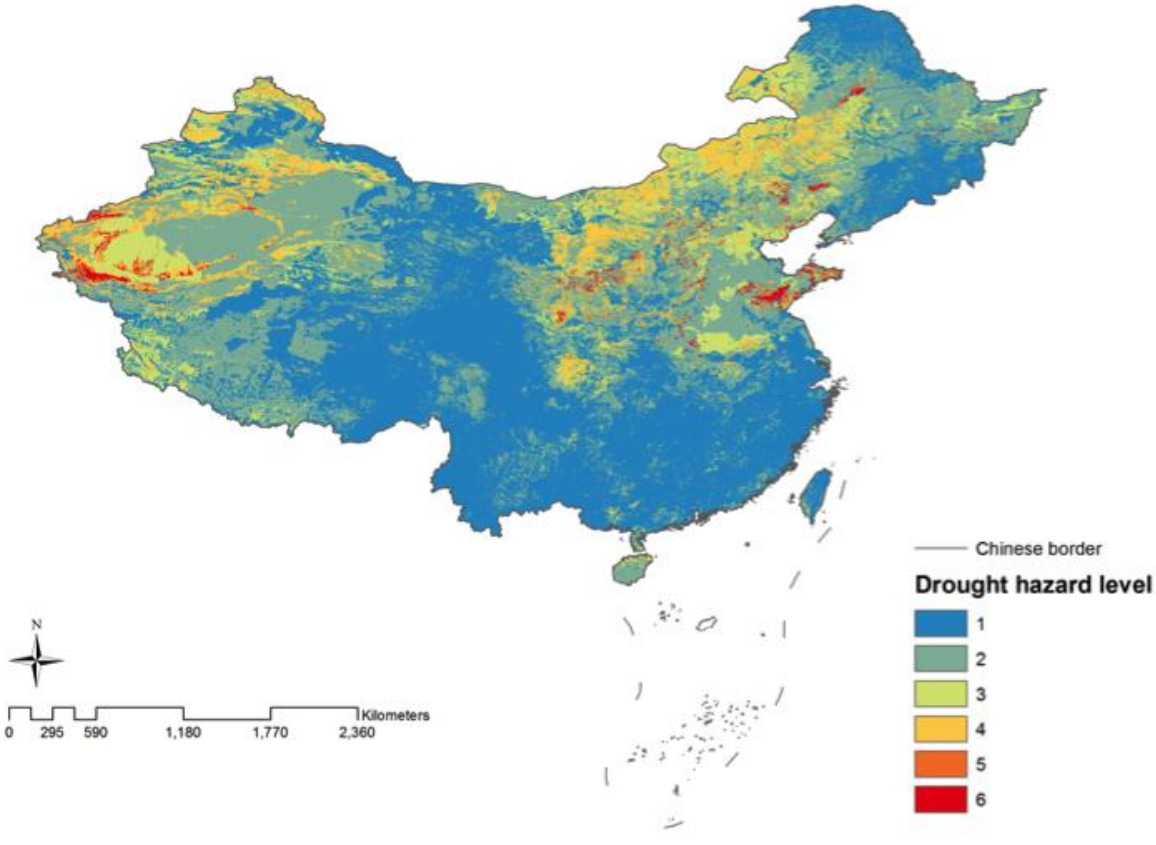

Figure 15. Drought hazard map

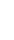

To verify the results, data were obtained from the "China Natural Disaster Database" which contains a record of natural disasters at county level, reported in Chinese provincial newspapers between 1949 and 2010 (Chinese Academy of Sciences 2015). The database includes information on the start and end times, location, disaster type, impact and journal sources.

Figure 16 below shows the historical records of drought events between 1949-2010 at county level. Darker red areas demonstrate higher incidents of flooding events. Blank cells contain no data. As can be seen from the figure below, between 1949--2010, drought events occurred mainly in northern China. 


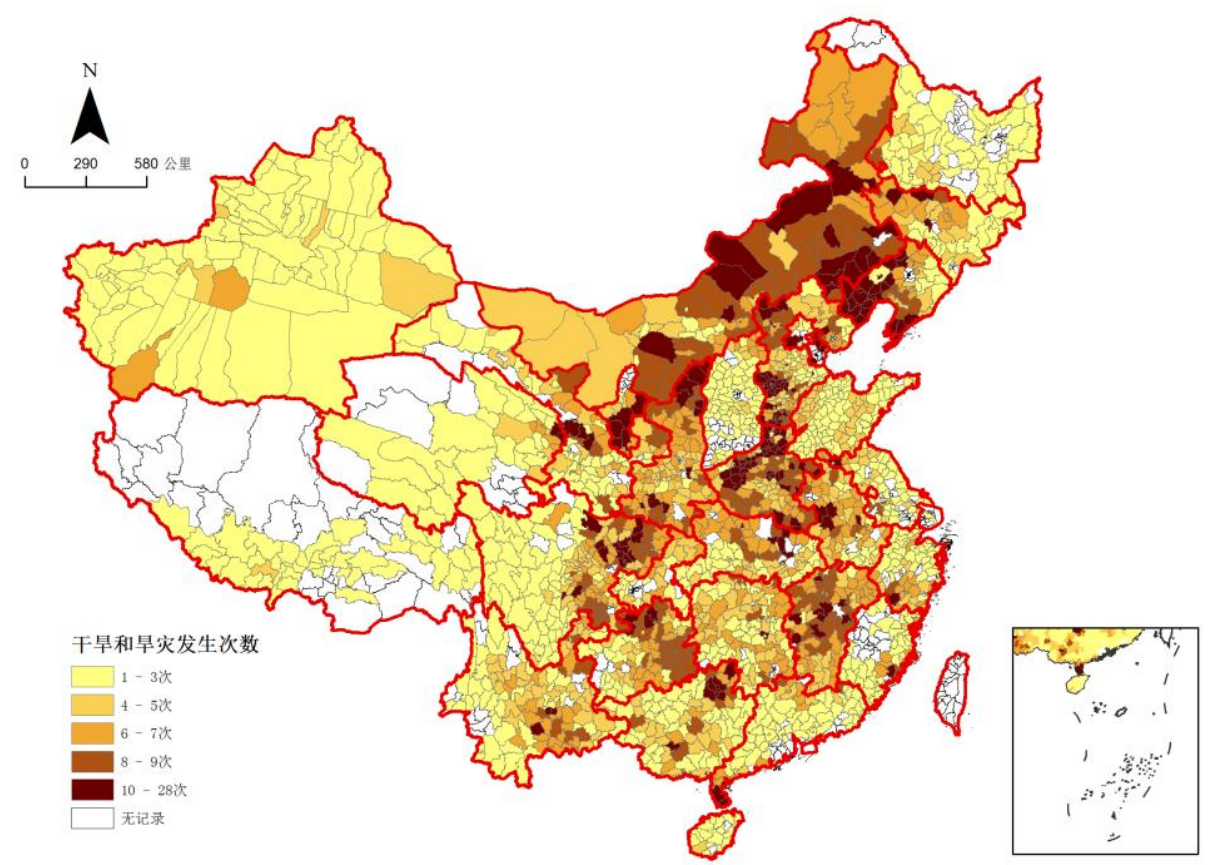

880

881

882

883

884

885

886

887

888

889

890

891

892

893

894

895

896

897

Figure 16. Drought frequency at county level, for example, the maroon counties have an aggregate drought frequency in the range of 10-28 between 1949 and 2010.

As counties contain multiple values of hazard level (Figure 15), the average hazard level was calculated for each county. The correlation between the average hazard level for that county was then plotted with the historical hazard frequency for that county. Pearson and Spearman correlation tests were conducted and it was demonstrated that the correlation between the hazard level map (Figure 15) and the historical map (Figure 16) is significant at 1\%. Results of the statistical tests are reported in the table below. For more verification details, please refer to the Atlas of Natural Disasters in China (Shi, 2011).

Table 8: Correlation between drought hazard map and historical drought map at county level

\begin{tabular}{lcc}
\hline \multirow{2}{*}{\multicolumn{1}{c}{ Test }} & \multicolumn{2}{c}{ Average hazard level per county } \\
\cline { 2 - 3 } & Coefficient & Significance \\
\hline Pearson & 0.176 & $0.000^{* * *}$ \\
Spearman & 0.165 & $0.000^{* *}$ \\
\hline
\end{tabular}

Notes: No. of observations $2118 ; * *$ at $1 \%$ significance level. 


\section{References}

899

900

901

902

903

904

905

906

907

908

909

910

911

912

913

914

915

916

917

918

919

920

921

922

923

924

925

926

927

928

929

930

931

932

933

Baiardi, F. \& Corò, F., 2013. GVScan: Scanning Networks for Global Vulnerabilities. In 2013 Eighth International Conference on Availability, Reliability and Security (ARES). Regensburg. Available at: http://ieeexplore.ieee.org/xpls/abs_all.jsp?arnumber=6657304 [Accessed February 8, 2014].

Bompard, E., Pons, E. \& Wu, D., 2013. Analysis of the structural vulnerability of the interconnected power grid of continental Europe with the Integrated Power System and Unified Power System based on extended topological approach Ettore. International Transactions on Electrical Energy Systems, 23(5), pp.620637. Available at: http://onlinelibrary.wiley.com/doi/10.1002/etep.1618/full [Accessed February 8, 2014].

China Academy of Transportation Sciences, 2005. Second National Inland Waterways Census (第二次全国内河航道普查) Ministry of Transport, ed., China Communications Press.

China Electric Power Yearbook Editorial Committee, 2011. Total Electricity Consumption in China in 2011 (2011 年全社会用电量), China Statistics Press.

Chinese Academy of Sciences, 2015. China Natural Disaster Database (中国自然灾 害数据库). Available at: http://www.data.ac.cn/zrzy/G52.asp [Accessed August 10, 2015].

Chinese Census Office of the State Council, 2012. Tabulation on the 2010 population census of the people's republic of china by county (中国2010人口 普查分县资料), China Statistics Press.

Civil Aviation Administration of China, 2008. 2020 National Plan for Civil Airports Layout （全国民用机场布局规划）.,pp.1-10. Available at: http://www.caac.gov.cn/I1/I2/200808/P020080819406619590745.pdf [Accessed April 4, 2014].

Civil Aviation Administration of China, 2013. Chinese airport traffic ranking 2012 (2012 民航机场业务量排名). Bulletin of The Chinese Aviation Industry (2012 全国机场生产统计公报), pp.7-9. Available at: http://www.caac.gov.cn/i1/K3/201303/t20130325_54626.html [Accessed May $1,2013]$.

Dankers, R. \& Feyen, L., 2008. Climate change impact on flood hazard in Europe: An assessment based on high-resolution climate simulations. Journal of Geophysical Research: Atmospheres, 113(19), pp.1-17. 
Davis, C.B. et al., 2014. Enipedia. Available at: http://enipedia.tudelft.nl/maps/PowerPlants.html [Accessed April 28, 2014].

Dinh, T. \& Xuan, Y., 2012. On new approaches of assessing network vulnerability: hardness and approximation. Networking, IEEE/ACM ..., 20(2), pp.609-619. Available at: http://ieeexplore.ieee.org/xpls/abs_all.jsp?arnumber=6051504 [Accessed February 10, 2014].

Dobbs, R. et al., 2013. Infrastructure productivity: How to save \$1 trillion a year, Available at: http://www.mckinsey.com/insights/engineering_construction/infrastructure_pro ductivity.

Dueñas-Osorio, L. \& Vemuru, S.M., 2009. Cascading failures in complex infrastructure systems. Structural Safety, 31(2), pp.157-167. Available at: http://linkinghub.elsevier.com/retrieve/pii/S016747300800057X [Accessed January 20, 2014].

Dutta, D., Herath, S. \& Musiake, K., 2003. A mathematical model for flood loss estimation. Journal of Hydrology, 277(1-2), pp.24-49. Available at: http://linkinghub.elsevier.com/retrieve/pii/S0022169403000842 [Accessed October 28, 2012].

Editorial Board of China Ports Yearbook, 2012. Port Summary. In China Ports Yearbook. China Ports Magazine. Available at: http://tongji.cnki.net/kns55/navi/HomePage.aspx $? \mathrm{id}=\mathrm{N} 2012060646 \&$ name $=\mathrm{YZ}$ GAW.

Erath, A. et al., 2009. Vulnerability Assessment of the Swiss Road Network. Transportation Research Record: Journal of the Transportation Research Board, 2137 (2009 Safety 2009: Security; Emergencies; Management; and School Transportation), pp.118-126. Available at: http://medcontent.metapress.com/index/A65RM03P4874243N.pdf [Accessed February 11, 2014].

Fang, W., 2011. Integrated Risk Governance: Database, risk maps and network platform, Beijing: Science China Press.

Hall, J.W. et al., 2014. Assessing the Long-Term Performance of Cross-Sectoral Strategies for National Infrastructure. Journal of Infrastructure Systems.

Hall, J.W., Sayers, P.B. \& Dawson, R.J., 2005. National-scale Assessment of Current and Future Flood Risk in England and Wales. Natural Hazards, 36(1-2), pp.147-164. Available at: http://link.springer.com/10.1007/s11069-004-4546-7.

Hines, P., Cotilla-Sanchez, E. \& Blumsack, S., 2010. Do topological models provide good information about electricity infrastructure vulnerability? Chaos 
992

993

994

995

996

997

998

999

1000

1001

1002

1003

1004 1005

(Woodbury, N.Y.), 20(3), p.033122. Available at: http://www.ncbi.nlm.nih.gov/pubmed/20887062 [Accessed February 2, 2014].

Hirabayashi, Y. et al., 2013. Global flood risk under climate change. Nature Publishing Group, 3(9), pp.816-821. Available at: http://dx.doi.org/10.1038/nclimate1911 Inpapers3://publication/doi/10.1038/ncli mate1911.

Holme, P. et al., 2002. Attack vulnerability of complex networks. Physical review, 65(5). Available at: http://www.ncbi.nlm.nih.gov/pubmed/12059649.

HSBC, 2012. No water, no power: is there enough water to fuel China's power expansion?, Hong Kong. Available at: http://chinawaterrisk.org/notices/chinawater-risk-and-hsbc-no-power-no-water-report/.

HSBC, 2011. Scoring Climate Change Risk, Hong Kong. Available at: http://www.google.com/url? sa $=\mathrm{t} \& \mathrm{rct}=\mathrm{j} \& \mathrm{q}=\&$ esrc $=\mathrm{s} \&$ source $=$ web $\& \mathrm{~cd}=1 \& \mathrm{ved}=$ 0CC4QFjAA\&url=http\%3A\%2F\%2Fwww.hsbc.com\%2F \%2Fmedia\%2FHSB C-com $\% 2$ Fabout-hsbc $\% 2$ Fin-the-future $\% 2$ Fpdfs $\% 2$ F111013-scoring-climatechange-risk.ashx\&ei=41QjU9XGJST0QXH4oHYCA\&usg=AFQjCNG_meSvMtf7krtVyYIA9chLIz20Q\&sig2=pFlfNOn0bjG8QjkScKopUA\&bvm=bv.62922401,d.d2k.

Hu, X., Hall, J.W. and Thacker, S. (2014) Too Big to Fail? The Spatial Vulnerability of the Chinese Infrastructure System to Flooding Risks. Vulnerability, Uncertainty and Risk: 704-714.

IPCC, 2012. Determinants of Risk: Exposure and Vulnerability. In Managing the Risks of Extreme Events and Disasters to Advance Climate Change Adaptation. pp. 65-108.

Johansson, J. \& Hassel, H., 2010. An approach for modelling interdependent infrastructures in the context of vulnerability analysis. Reliability Engineering \& System Safety, 95(12), pp.1335-1344. Available at: http://linkinghub.elsevier.com/retrieve/pii/S0951832010001444 [Accessed January 27, 2014].

Jongman, B. et al., 2014. Increasing stress on disaster-risk finance due to large floods. Nature Climate Change, 4(4), pp.1-5.

Kim, H. et al., 2009. Role of rivers in the seasonal variations of terrestrial water storage over global basins. Geophysical Research Letters, 36(17), pp.2-6.

KPMG, 2009. Infrastructure in China : Foundation for growth, Hong Kong. Available at: http://www.kpmg.de/docs/Infrastructure_in_China.pdf. 
KPMG, 2008. Transport in China, Hong Kong. Available at: http://www.kpmg.com/CN/en/IssuesAndInsights/ArticlesPublications/Documen ts/transport-china-0804.pdf.

LaRocca, S. et al., 2012. Comparing Topological Performance Measures and Physical Flow Models for Vulnerability Analysis of Power Systems. Psam1 1 \& Esrel2012, 35(4), pp.608-623. Available at: http://lup.lub.lu.se/record/2337670.

Lewis, J.I., 2009. Climate change and security: examining China's challenges in a warming world. International Affairs, 85(6), pp.1195-1213. Available at: http://doi.wiley.com/10.1111/j.1468-2346.2009.00857.x.

Li, K. et al., 2012. Flood loss analysis and quantitative risk assessment in China. Natural Hazards, 63(2), pp.737-760. Available at: http://www.springerlink.com/index/10.1007/s1 1069-012-0180-y [Accessed November 5, 2012].

Lim WH et al (n.d.) Long-term changes in global river flood frequency, socioeconomic benefits of flood defences and residual risk based on CMIP5 climate models (in preparation)

Mao, Z. et al., 2009. Vulnerability Analysis of Urban Infrastructures. 2009 International Conference on Industrial and Information Systems, pp.395-398. Available at: http://ieeexplore.ieee.org/lpdocs/epic03/wrapper.htm?arnumber=5116381 [Accessed January 26, 2014].

Marrone, S., Nardone, R. \& Tedesco, A., 2013. Vulnerability modeling and analysis for critical infrastructure protection applications. ... Infrastructure Protection, 6(3-4), pp.217-227. Available at: http://linkinghub.elsevier.com/retrieve/pii/S1874548213000462 [Accessed February 15, 2014].

Matisziw, T.C., Murray, A.T. \& Grubesic, T.H., 2009. Exploring the vulnerability of network infrastructure to disruption. The Annals of Regional Science, 43(2), pp.307-321. Available at: http://link.springer.com/10.1007/s00168-008-0235-x [Accessed February 12, 2014].

Ministry of Rail, 2010. Chinese Railway Passenger Train Timetable（全国铁路旅 客列车时刻表), China Railway Publishing House.

Ministry of Rail, 1980. Classification of Chinese Railway Stations 《铁路车站等级 核定办法》。 
1040

1041

1042

1043

1044

1045

1046

1047

1048

1049

1050

1051

1052

1053

1054

1055

1056

1057

1058

1059

1060

1061

1062

1063

1064

1065

1066

1067

1068

1069

1070

1071

1072

1073

1074

1075

Ministry of Rail, 2012. Ministry of Rail: Bulletin of the 2012 Chinese Railway (中华 人民共和国铁道部 2012 年铁道统计公报)., pp.1-5. Available at: http://finance.china.com.cn/roll/20130313/1327154.shtml.

Ministry of the Environment, 2013. Statistics on national urban sewage treatment facilities in China (全国投运城镇污水处理设施清单)., pp.1-204. Available at:

http://www.mep.gov.cn/gkml/hbb/bgg/201305/W020130508476747765965.pdf.

Ministry of Water Resources, 2011. Bulletin of Flood and Drought Disasters in China (中国水旱灾害公报), Available at: http://www.mwr.gov.cn/zwzc/hygb/zgshzhgb/201212/t20121212_334746.html.

Ministry of Water Resources, 2012. Bulletin of Flood and Drought Disasters in China (中国水旱灾害公报), Available at: http://www.mwr.gov.cn/zwzc/hygb/zgshzhgb/201311/t20131104_515863.html.

Mishra, A.K. \& Singh, V.P., 2010. A review of drought concepts. Journal of Hydrology, 391(1-2), pp.202-216. Available at: http://linkinghub.elsevier.com/retrieve/pii/S0022169410004257 [Accessed May 24, 2014].

NOAA, 2015. F18 2012 Nighttime Lights Composite. Version 4 DMSP-OLS Nighttime Lights Time Series. Available at: http://ngdc.noaa.gov/eog/dmsp/downloadV4composites.html [Accessed July 20, 2015].

OpenStreetMap Contributors, 2014. OpenStreetMap. Available at: https://www.openstreetmap.org/about [Accessed May 5, 2014].

Oswald, M. \& Treat, C., 2013. Assessing Public Transportation Vulnerability to Sea Level Rise: A Case Study Application. Journal of Public Transportation, (Fta 2011), pp.59-77. Available at: http://www.nctr.usf.edu/wpcontent/uploads/2013/10/16.3_oswald.pdf [Accessed February 8, 2014].

Ouyang, M. et al., 2009. A methodological approach to analyze vulnerability of interdependent infrastructures. Simulation Modelling Practice and Theory, 17(5), pp.817-828. Available at: http://dx.doi.org/10.1016/j.simpat.2009.02.001 [Accessed February 13, 2014].

Ouyang, M. et al., 2014. Comparisons of complex network based models and real train flow model to analyze Chinese railway vulnerability. Reliability Engineering \& System Safety, 123, pp.38-46. Available at: http://linkinghub.elsevier.com/retrieve/pii/S0951832013002792 [Accessed February 13, 2014]. 
Pappenberger, F. et al., 2012. Deriving global flood hazard maps of fluvial floods through a physical model cascade. Hydrology and Earth System Sciences, 16(11), pp.4143-4156.

Regmi, M.B. \& Hanaoka, S., 2011. A survey on impacts of climate change on road transport infrastructure and adaptation strategies in Asia. Environmental Economics and Policy Studies, 13(1), pp.21-41. Available at: http://www.springerlink.com/index/10.1007/s10018-010-0002-y [Accessed November 26, 2012].

De Sherbinin, A., Schiller, A. \& Pulsipher, A., 2007. The vulnerability of global cities to climate hazards. Environment and Urbanization, 19(1), pp.39-64. Available at: http://eau.sagepub.com/cgi/doi/10.1177/0956247807076725 [Accessed November 17, 2012].

BeijingShi, P. ed., 2011. Atlas of Natural Disaster Risk in China（中国自然灾害风 险地图集）, Beijing: Science China Press.

Shuang, Q., Zhang, M. \& Yuan, Y., 2014. Node vulnerability of water distribution networks under cascading failures. Reliability Engineering \& System Safety, 124, pp.132-141. Available at: http://linkinghub.elsevier.com/retrieve/pii/S0951832013003153 [Accessed February 14, 2014].

Stanway, D., 2011. China power crunch to worsen as drought slashes hydro. Reuters. Available at: http://www.reuters.com/article/2011/05/25/us-china-droughthydropower-idUSTRE74O1BK20110525 [Accessed August 26, 2015].

State Grid Energy Research Institute, 2014. Large-scale Ultra High Voltage Transmission is in rapid development in China (特高压跨区输电应更大规模 地快速发展). China National Grid Highlight Report. Available at: http://www.sgeri.sgcc.com.cn/html/sgeri/col1080000035/201411/14/20141114105657125741045_1.html [Accessed July 15, 2015].

Takata, K., Emori, S. \& Watanabe, T., 2003. Development of the minimal advanced treatments of surface interaction and runoff. Global and Planetary Change, 38(1-2), pp.209-222.

Tang, H.S. et al., 2013. Vulnerability of population and transportation infrastructure at the east bank of Delaware Bay due to coastal flooding in sea-level rise conditions. Natural Hazards, 69(1), pp.141-163. Available at: http://link.springer.com/10.1007/s11069-013-0691-1 [Accessed February 14, 2014].

The Harvard WorldMap Project, 2014. Harvard ChinaMap. Available at: http://worldmap.harvard.edu/chinamap/ [Accessed April 28, 2015]. 
1113

1114

1115

1116

1117

1118

1119

1120

1121

1122

1123

1124

1125

1126

1127

1128

1129

1130

1131

1132

1133

1134

1135

1136

1137

1138

1139

1140

1141

1142

1143

1144

1145

1146

1147

1148

Wang, S. et al., 2013. Vulnerability analysis of interdependent infrastructure systems under edge attack strategies. Safety Science, 51(1), pp.328-337. Available at: http://linkinghub.elsevier.com/retrieve/pii/S0925753512002007 [Accessed February 14, 2014].

Wang, S., Hong, L. \& Chen, X., 2012. Vulnerability analysis of interdependent infrastructure systems: A methodological framework. Physica A: Statistical Mechanics and its Applications, 391(11), pp.3323-3335. Available at: http://linkinghub.elsevier.com/retrieve/pii/S0378437111009794 [Accessed August 5, 2014].

Ward, P.J. et al., 2013. Assessing flood risk at the global scale: model setup, results, and sensitivity. Environmental Research Letters, 8(4), p.044019. Available at: http://stacks.iop.org/1748-

9326/8/i=4/a=044019?key=crossref.2ecb02eb38c1de207a81abed549fe415 [Accessed May 22, 2014].

Wilhelmi, O. V \& Wilhite, D.A., 2002. Assessing Vulnerability to Agricultural Drought: A Nebraska Case Study. Drought Mitigation Center Faculty Publications.

World Bank, 2007. An Overview of China's Transport Sector - 2007.

World Bank, 2004. Understanding the Economic and Financial Impacts of Natural Disasters, Washington, DC. Available at:

http://elibrary.worldbank.org/doi/book/10.1596/0-8213-56852?queryID=987\%2F1899984.

World Bank, 2005. Waste Management in China: Issues and Recommendations May 2005.

Wu, S., Pan, T. \& He, S., 2012. Climate Change Risk Research : A Case Study on Flood Disaster Risk in China. , 3(2), pp.92-98.

Xie, J. et al., 2013. Board-scale reliability of the flood defence infrastructure within the Taihu Basin , China. Journal of Flood Risk Management, 6(1), pp.42-56.

Yamazaki, D. et al., 2011. A physically based description of floodplain inundation dynamics in a global river routing model. Water Resources Research, 47(4), pp.1-21.

Yamazaki, D. et al., 2014. Water Resources Research. Water Resources Research, 50, pp.3467-3480.

Yin, N., 2010. Chinese high-speed rail can breakeven (中国高铁实现盈亏平衡没有 悬念). Xinhua News. Available at: http://jjckb.xinhuanet.com/cjxw/201008/12/content_248195.htm [Accessed July 11, 2015]. 
1149 Zarafshani, K. et al., 2012. Drought vulnerability assessment: The case of wheat 1150 farmers in Western Iran. Global and Planetary Change, 98-99, pp.122-130.

$1151 \quad$ Available at: http://linkinghub.elsevier.com/retrieve/pii/S0921818112001762

1152 [Accessed November 29, 2012].

1153

1154

1155

1156

\section{Ethical Statement}

1158

1159 This statement confirms that the work presented in this paper complies with all the

1160 requirements in sections "Ethical Responsibilities of Authors", "Ethical Standards"

1161 and "Disclosure of Potential Conflicts of Interest" of the Journal of Natural 1162 Hazards.

1163

1164

1165

1166 